\title{
The Study of the Spatial Heterogeneity and Structural Evolution of the Producer Services Trade Network
}

\author{
Yan Li $(\mathbb{D}$, Xuehan Liang $\mathbb{D}$, and Qingbo Huang $(\mathbb{D}$ \\ School of Maritime Economics and Management, Dalian Maritime University, Dalian 116026, China \\ Correspondence should be addressed to Qingbo Huang; huangqingbo@dlmu.edu.cn
}

Received 21 December 2020; Revised 7 April 2021; Accepted 12 April 2021; Published 26 April 2021

Academic Editor: Huajiao Li

Copyright (c) 2021 Yan Li et al. This is an open access article distributed under the Creative Commons Attribution License, which permits unrestricted use, distribution, and reproduction in any medium, provided the original work is properly cited.

\begin{abstract}
Constructing an all-directional, multilevel, and composite interconnection network, accelerating the free flow of producer services elements across regions, and further improving the efficiency of resource integration demand to conduct a comprehensive and systematic analysis of producer services trade. Thus, using bilateral trade data, this paper builds producer services trade network composed of 61 major countries and innovatively combines the methods of social network and economic geography to explore its spatiotemporal evolution and system properties. The results show that, firstly, the producer services trade network has spatial heterogeneity, which is characterized by high-value agglomerations in Western Europe and East Asia, and low-value agglomerations in Southern Europe and Southeast Asia. Secondly, most countries tend to choose trading partners with close geographical locations or common cultures to establish a cohesive subgroup. Thirdly, the producer services trade network has a significant core-periphery structure, the "spaghetti bowl" effect, which leads to a downward trend in the number of core and semiperipheral countries. Finally, the trade agreement relations, language relations, and differences in economy, geography, institution, and technology all have a significant impact on the evolution of producer services trade network, but this change has little relationship with the population size divergences of different countries.
\end{abstract}

\section{Introduction}

As the world economy has presented a trend of transformation from industrial type to being service-oriented, the service industry has become the focus of international trade, among which producer services industry is the most critical branch because it gathers a lot of knowledge and capital $[1,2]$. Affected by the application of information technology $[3,4]$, the elements of producer services are redistributed in the global market; more countries carry out trade activities as exporters or importers, thus forming a gigantic relationship network of producer services trade. Whether it can become a key node with control power in producer services trade network determines the construction of a "servicedriven country," and reflects the position of international division of labor and the distribution of interests in the economic globalization. Therefore, it is of great significance to study the spatiotemporal evolution and the complex features of producer services trade network for complementing the study of competitiveness evaluation based on trade volume accounting and formulating adaptive and feasible trade strategies. It is also the practice of network analysis method in a specific industry level.

Along with global economic integration, more mainstream standpoints can recognize the conclusion that the producer services can be a major component of trade flow for a long time [5]. In 1995, the General Agreement on International Trade in service (GATS), which was led by WTO, came into force. As a result of the unbalanced development of service industry in various countries and the differences in negotiations, the liberalization of services trade under the framework of GATS has made slow progress, and regional services trade agreements have gradually sprung up, such as the "Trans-Pacific Partnership Agreement (TPP)" and "International Trade in Services Agreement (TISA)." These changes in regional economic and trade cooperation also increase the uncertainty of the future development of the producer services trade network. 
Moreover, the enhancement of the extroversion characteristics of producer services has changed the view of the traditional urban basic economic model [6], that is, "services can only be sold within a limited distance, and cannot be exported to other regions to generate income for the local area." Since then, the spatial flow of producer services gradually infiltrates into regional or urban research areas. Majority of those studies focus on the location selection and driving factors of producer services enterprises, or the spatial agglomeration and influence mechanism of industry at the micro level [7-9]. However, there are few studies that combine the spatial heterogeneity of producer services with macro trade data and use the network method to analyze.

The purpose of this article was to capture the dynamic and heterogeneous features of producer services trade network, and focus on the following issues: What are the spatial characteristics and influencing factors of the structural evolution of producer services trade network? Has the development of producer services in emerging economies changed their position in the trade network and the pattern of global interests? Are the core countries and the marginal countries regularly carrying out trade interaction to promote them to integrate into producer services trade network? The solution of these problems will help to optimize the trade network structure, and build an all-directional, multilevel, composite interconnection network.

The main contributions are as follows: firstly, previous studies, reviewed in Sections 1 and 2, are mostly based on the micro perspective of industry and enterprise, or the analysis of commodity trade network. This paper makes up for the gap of service trade network from the global and national macro level. Secondly, the social network analysis method is introduced into the field of producer services trade to identify the functions of different countries in trade network and the factors affecting the evolution of network structure, and to supplement the methods of competitiveness evaluation and previous empirical studies limited to the dual relationship between the two sides of trade. Finally, applying GIS technology to trade data for spatial exploratory analysis, this paper expands the research content related to economic geography, reveals the general characteristics and evolution law of producer services trade network, and provides scientific support for the establishment of an open and inclusive services trade system.

The rest of the research mainly consists of four parts. Section 2 is literature review. Section 3 includes an overview of the research area, data sources, and methods of this article. Section 4 describes the spatiotemporal characteristics and impact factors of producer services trade network, and the final part puts forward conclusions, policy recommendations, and the future research directions.

\section{Literature Review}

Taking trade network as an example, the complexity of the socioeconomic system is an interdisciplinary issue that combines economics, geography, and network science [10-13]. Only by establishing a multiple analysis framework can we holistically explore its structure and evolution trend.
However, most of the existing researches on the producer services trade system are based on a single dimension, mainly including two categories. The first category is about the perspective of economics. These studies focus on the driving mechanism of the development of producer services trade and its basic role in the transformation and upgrading of economic structure. Research and development investment, infrastructure construction, and foreign investment are considered as the essential elements to enhance the competitiveness of producer services trade $[14,15]$. In terms of the utility in macroeconomic operation, producer services trade can provide key missing factors for final products and improve domestic total factor productivity through technology transfer and spillover [16]. The second category focuses on the geographical perspective. These studies point out that the producer services trade flow structure is composed of export cities, circulation systems, and market cities, and find that the role of producer service trade in regional and urban system is such that its unbalanced distribution will bring about the adjustment of regional economic structure, thus leading to the outward development of service trade [17].

Related research methods have become more abundant over time. Traditional analytical approaches mainly include simple international comparison based on revealed comparative advantage index or trade competitiveness index, and applying classical gravity model or other econometric methods to investigate the binary relationship between trade subjects [18, 19]. Social network is an emerging systematic method [20]. Since the scale-free network was proposed, using this method to analyze international trade issues has become the focal point of most researches [21-25]. In particular, Quadratic Assignment Procedure (QAP) belongs to the hypothesis test of "relationship-relationship" level in the social network method, which is considered to be one of the most effective tools for empirical analysis of network science $[26,27]$. However, the objects of existing studies are mainly the goods trade network [28-30]. Limited by the difficulty of bilateral data acquisition, only a few literatures focus on the services trade network. Xu uses QAP weighted network to find that there is a significant correlation between various sectors of services trade. When exploring the impact of common human relations on the services trade network, he believes that common trade agreements play the most critical role, and the same language and religion are also major determinants [31, 32]. Besides, QAP regression analysis also shows that the differences of economic scale, technological innovation, and geographical distance affect the changes of services trade network structure in the region [33].

Summing up previous studies, we can find that there are still some deficiencies in the comprehensive application of economic geography and network theory to analyze the producer services trade relationship. Considering its strategic significance in the global industrial network and value chain, as well as the gaps in related fields, we explore the spatial-temporal variation and influencing factors of the producer services trade network, lay an empirical foundation for its balanced development, and put forward policy 
suggestions for effectively improving the status of countries in the trade network.

\section{Research Methods and Data Sources}

3.1. Data Sources and Trade Network. The primary trade data source of this study is the OECD database. Based on the latest available annual data of producer services trade in 2000, 2004, 2008, and 2012, 61 countries $^{1}$ with total services trade accounting for more than $90 \%$ of the world's total services trade are involved, covering major economies in the world. The classification standard of producer services refers to the definitions of Browning and Singlemann [34], which mainly include six subindustries, namely: (1) transportation industry; (2) communication industry; (3) finance industry; (4) insurance industry; (5) computer and information services industry; and (6) concession rights and patent royalties, integrating the data of various industries to establish the producer services trade network. The logical framework of this paper is as follows (Figure 1):

The complex system $G$ of trade network can be represented by a tuple: $G=(V, E)$. Among them, $V=\left\{v_{1}, v_{2}, \ldots, v_{n}\right\}$ is the node set, $E=\left\{e_{i j}\right\}$ is the edge set, and each edge $e_{i j}$ in $E$ has a pair of nodes $\left(v_{i}, v_{j}\right)$ in $V$ corresponding to it.

In this paper, we use 61 sample countries and the trade flows between countries as nodes and edges, respectively, to construct trade network. The adjacency matrix $A=\left[a_{i j}\right]$ denotes the unweighted network. If there is a trade relationship between the two countries, $a_{i j}=1$, otherwise $a_{i j}=0$, in the undirected network, $a_{i j}=a_{j i}$. The adjacency matrix $W=\left[w_{i j}\right]$ represents the weighted trade network. In the directed network, the edge weight is expressed by the export volume (million US dollars) from $v_{i}$ to $v_{j}$. In the undirected network, the total trade volume (million US dollars) between $v_{i}$ and $v_{j}$ is used to represent the edge weight, that is, $w_{i j}=w_{j i}$. Where $w_{i j}=w_{i j}^{e}+w_{i j}^{m},(i, j=$ $1,2, \ldots, n), w_{i j}^{e}\left(w_{i j}^{m}\right)$ represents the trade amount that the $v_{i}$ exports (imports) to $v_{j}$. Referring to Cerina's method [35], set 100 million US dollars as the threshold of trade flows, the trade volume of each network after taking the threshold value over the years accounts for more than $90 \%$ of the total trade volume of the corresponding fully connected trade network, which indicates that the network after extracting the threshold value is relatively representative. After determining the threshold value, the edge whose trade flows is greater than it is assigned to 1 , otherwise it is assigned to 0 , so as to halve the weighted network to obtain the unweighted trade network.

\subsection{Research Methods}

3.2.1. Network Analysis. Social network analysis is a comprehensive method to analyze the structure and attribute of "social actors as nodes and their relationship set"; this method is widely used in investment relations, population migration, and knowledge spillover relations because it can reveal the network structural features from multiple angles [36]. The selection and analysis of specific research indicators in this paper are carried out according to the following ideas: the first is the overall analysis of the network, which aims to explore the whole evolutionary trend, including network density, average degree, average path length, and average clustering coefficient. The second is the node analysis of the network, which studies the status and function of trade entities in the network, including degree centrality, closeness centrality, and betweenness centrality, and the node strength. Finally, the cohesive subgroup structure and core-periphery structure are synthetically determined based on the index features to divide the subgroups and levels in the network. Relevant indicators are shown in Table 1.

3.2.2. Empirical Model. The existing literatures usually consider the influence of economic scale, geographical distance, and institutional differences on trade relations and flows $[37,38]$. In addition, participating in common regional trade agreements may reduce the cost of trade, but it is necessary to pay attention to the negative effects due to their asymmetric impact on countries [39]. The function of informal institutions such as culture in trade cannot be ignored, Selmier et al. pointed out that the positive communication of language culture will reduce the blind area of bilateral trade cognition and the cost of information acquisition [40]. Because the producer services are technology-intensive industries, technological innovation also plays a major role in the development of producer services trade [33]. Besides, affected by trade demands and transaction markets, population size may change the global trade pattern [41].

Based on this, we build the following model to analyze the factors influencing the evolution of producer services trade network:

$Y=F($ Dis_gdp, Comfta, Dis_cap, Dis_ins, Comlan, Dis_tec, Dis_pop $)$,

where $Y$ is the producer services trade relation matrix; Dis_gdp, Dis_cap, Dis_ins, Dis_tec, Dis_pop represent the differences in economic scale, geographical distance, institution, technology, and population size, respectively, while Comfta and Comlan represent the trade agreement and language relationship between the two countries; the specific variable representation and data sources are shown in Table 2.

The variables belong to relational data and have structural autocorrelation; traditional multiple regression analysis based on ordinary least squares cannot reflect the correlation between them. QAP regression is a 


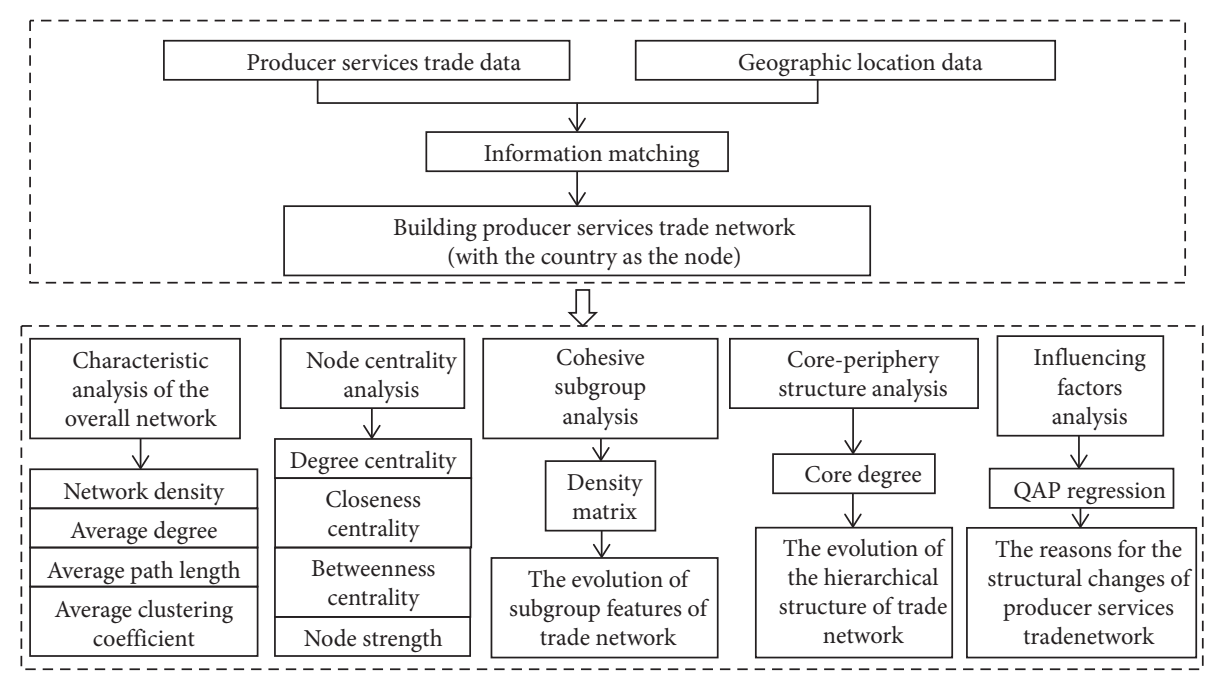

Figure 1: Logical framework.

TABLE 1: Network analysis indicators.

\begin{tabular}{|c|c|c|}
\hline Indicators & Formulation & Index explanation \\
\hline Network density & $D=(2 m /(n(n-1)))$ & $\begin{array}{l}D \text { refers to the proportion of the actual } \\
\text { number of node connections in the } \\
\text { network to the maximum number of } \\
\text { possible node connections. }\end{array}$ \\
\hline Average degree & $\bar{k}=(1 / n) \sum_{i}^{n} k\left(v_{i}\right)$ & $\begin{array}{c}\bar{k} \text { refers to the average of the degrees of } \\
\text { all nodes, } k\left(v_{i}\right) \text { represents the degree } \\
\text { of node. } v_{i} .\end{array}$ \\
\hline $\begin{array}{l}\text { Average path } \\
\text { length }\end{array}$ & $L=(1 /(n(n-1))) \sum_{i, j} d_{i j}$ & $\begin{array}{l}L \text { refers to the average number of the } \\
\text { shortest path between each pair of } \\
\text { nodes, } d_{i j} \text { represents the shortest path } \\
\text { between nodes } v_{i} \text { and } v_{j} \text {. }\end{array}$ \\
\hline $\begin{array}{l}\text { Average } \\
\text { clustering } \\
\text { coefficient }\end{array}$ & $\begin{array}{l}\bar{C}=(1 / n) \sum_{i=1}^{n} C\left(v_{i}\right) \\
=(1 / n) \sum_{i=1}^{n}\left(\sum_{j, k \in G} a_{i j} a_{j k} a_{k i} / k\left(v_{i}\right)\left(k\left(v_{i}\right)-1\right)\right)\end{array}$ & $\begin{array}{l}\bar{C} \text { is the mean value of the clustering } \\
\text { coefficients of all nodes. } C\left(v_{i}\right) \\
\text { represents the clustering coefficient of } \\
\text { node } v_{i} \text {. }\end{array}$ \\
\hline
\end{tabular}

$\begin{aligned} & \text { Degree } \\ & \text { centrality }\end{aligned} C_{D}\left(v_{i}\right)=\left(\left(\sum_{j=1}^{n} a_{i j}(i \neq j)\right) /(n-1)\right)$ $\begin{gathered}C_{D}\left(v_{i}\right) \text { describes the ability of direct } \\ \text { contact of node } v_{i} \text { with others. }\end{gathered}$

The possibility of direct trade links between a country and other countries.

$\begin{aligned} & \text { Closeness } \\ & \text { centrality }\end{aligned} C_{C}\left(v_{i}\right)=\left((n-1) / \sum_{v_{j} \in V, i \neq j} d_{i j}\right)$

$C_{C}\left(v_{i}\right)$ refers to the sum of the shortest path between an individual node and all other nodes.

Actual meaning

The activity of producer services trade links among countries.

The connectivity of the whole trade network.

The transmission efficiency of trade network.

The degree of aggregation and adjacency of trade network.

The relative spatial accessibility of countries in trade network.

$C_{B}\left(v_{i}\right)$ refers to the probability that a node is in the shortcut between node

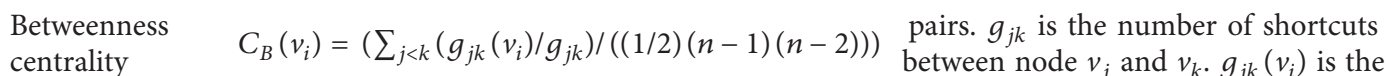
centrality between node $v_{j}$ and $v_{k} \cdot g_{j k}\left(v_{i}\right)$ is the number of shortcuts between node $v_{j}$ and $v_{k}$ that passes through the node $v_{i}$. $S\left(v_{i}\right)$ is the sum of weights of all edges connected to the node $v_{i}$. In the Node strength $\quad S\left(v_{i}\right)=\sum_{j=1}^{n} a_{i j} w_{i j}$ directed network, it can be divided into out-strength and in-strength.

The transfer function of countries in trade network.

By iterating different pattern matrices $\delta$ to obtain the maximum value $\rho$. At this time, $\delta$ is the actual corresponding core-periphery structure matrix. $c$

Core degree $\quad \rho=\sum_{i, j} a_{i j} \delta_{i j} \delta_{i j}=c_{i} \times c_{j}$ represents the core degree of node, $a_{i j}$ is the element in adjacency matrix $A$, $\delta_{i j}$ is the element in pattern matrix $\delta$ of the core-periphery structure, and $\rho$ represents the correlation between matrix Aand matrix $\delta$. 
TABLe 2: Variable description and data sources.

\begin{tabular}{|c|c|c|}
\hline Driving factors & Variable description & Data sources \\
\hline $\begin{array}{l}\text { Economic scale } \\
\text { difference }\end{array}$ & The absolute difference of GDP growth rate between $v_{i}$ and $v_{j}$ countries. & $\begin{array}{l}\text { The WDI } \\
\text { database }\end{array}$ \\
\hline $\begin{array}{l}\text { Trade agreement } \\
\text { relation }\end{array}$ & If countries $v_{i}$ and $v_{j}$ have a common trade agreement, it is 1 , otherwise it is 0 . & $\begin{array}{l}\text { The CEPII } \\
\text { database }\end{array}$ \\
\hline $\begin{array}{l}\text { Geographical distance } \\
\text { difference }\end{array}$ & The actual distance between the capitals of $v_{i}$ and $v_{j}$ countries. & $\begin{array}{l}\text { The CEPII } \\
\text { database }\end{array}$ \\
\hline Institutional difference & $\begin{array}{l}\text { The calculation formula is: Dis_ins }=(1 / 6) \sum_{h}^{6}\left|\left(\left(I_{i h}-I_{j h}\right) /\left(\max I_{h}-\min I_{h}\right)\right)\right|, h \text { represents six } \\
\text { dimensions to measure the national institution, namely, control of corruption, government } \\
\text { effectiveness, political stability and absence of violence, regulatory quality, rule of law, voice and } \\
\text { accountability, } I_{h} \text { represents the score on the } h \text { dimension [42]. }\end{array}$ & $\begin{array}{l}\text { The WGI } \\
\text { database }\end{array}$ \\
\hline Language relationship & If countries $v_{i}$ and $v_{j}$ have common official language, it is 1 , otherwise it is 0. & $\begin{array}{l}\text { The CEPII } \\
\text { database }\end{array}$ \\
\hline Technical difference & The absolute difference in the number of patent applications between $v_{i}$ and $v_{j}$ countries. & $\begin{array}{l}\text { The WDI } \\
\text { database }\end{array}$ \\
\hline $\begin{array}{l}\text { Population size } \\
\text { difference }\end{array}$ & The absolute difference in population scale between $v_{i}$ and $v_{j}$ countries. & $\begin{array}{l}\text { The CEPII } \\
\text { database }\end{array}$ \\
\hline
\end{tabular}

nonparametric test method, which is used to analyze the regression relationship between multiple matrices and one matrix, avoiding the error problem caused by data "multicollinearity" in traditional measurement methods. Therefore, we use the method of QAP regression to explore the factors that affect the structural changes of producer services trade network.

\section{Spatial Analysis of the Topological Feature of the Producer Services Trade Network}

4.1. Spatial Pattern Evolution of the Producer Services Trade Network. This paper uses ArcGIS 10.4 to take countries as network nodes, the bilateral import and export volume of producer services trade as weight, and selects the data of four time periods of 2000, 2004, 2008, and 2012 to construct the structure chart of undirected producer services trade network to study its spatial and temporal evolution.

The evolution of producer services trade pattern can be described simply by the node strength of each country and trade flows between countries. The following conclusions can be drawn from Figure 2: the node strength of each country and the edge weight of neighboring node countries were increasing, and the trade links among countries were closer, forming an integrated and interdependent trade network. The reason is that the deepening of economic globalization and the adjustment strategy of industrial structure incline to service industry, the status of producer services industry in the domestic economy is rising, and the trade development continues to be active. Except for the most significant trade volume between the United States and Japan in 2000, the scale of producer services trade between the United Kingdom and the United States was the largest in the remaining years. Because spatial proximity was an important driving factor for the occurrence of regional trade phenomena, other closely related trading partners were generally countries with closer geographical location, such as Germany-the United Kingdom, the United KingdomFrance, the United States-Canada, the United States-Mexico.
The establishment of the North American Free Trade Area and the foundation of the European Union also promoted intra-regional trade links. Since the United States was the absolute core of the trade network, and the trade mode has evolved from intra-regional clusters to trans-continental trade (such as the United States-China, the United StatesIndia), the spatial pattern of producer services trade network has gradually transformed from a dual-core pattern of "the United States-Western Europe" to a cross-regional radial pattern with the United States as the explosive point.

The change of international demand structure and the difference of industrial chain status in different countries lead to more and more regional and national imbalances in the development of producer services trade, which is reflected in the spatial heterogeneity in the network. The whole network presented two high-value trade concentration regions, namely, East Asia and Western Europe. Southern European countries, such as Croatia, Bulgaria and Slovenia, as well as Southeast Asian countries, such as Cambodia, Vietnam, and Brunei, have formed low-scale trade agglomeration areas in space. In terms of node significance, the most critical trade nodes in North America were the United States and Canada, and the United States had the highest node strength each year. Other developed countries such as Germany, the United Kingdom and France, as secondary links, occupied the central position and supported the development of trade network. Before 2008, China, South Korea, Singapore, and Japan were essential nodes in the Asian region. After 2008, policy reform, technological progress, deepening division of labor, investment inclination, and other factors have jointly promoted the growth of producer services in India, so it became another vital node in Asia. This shows that in recent years, the status of a subset of emerging economies in the producer services trade network has risen, but it has not gradually changed the leading position of developed countries.

Over time, geographical factors were no longer a factor restricting trade exchanges, and the degree of trade globalization was strengthening, so the trade links between various countries were characterized by diversification. For example, 


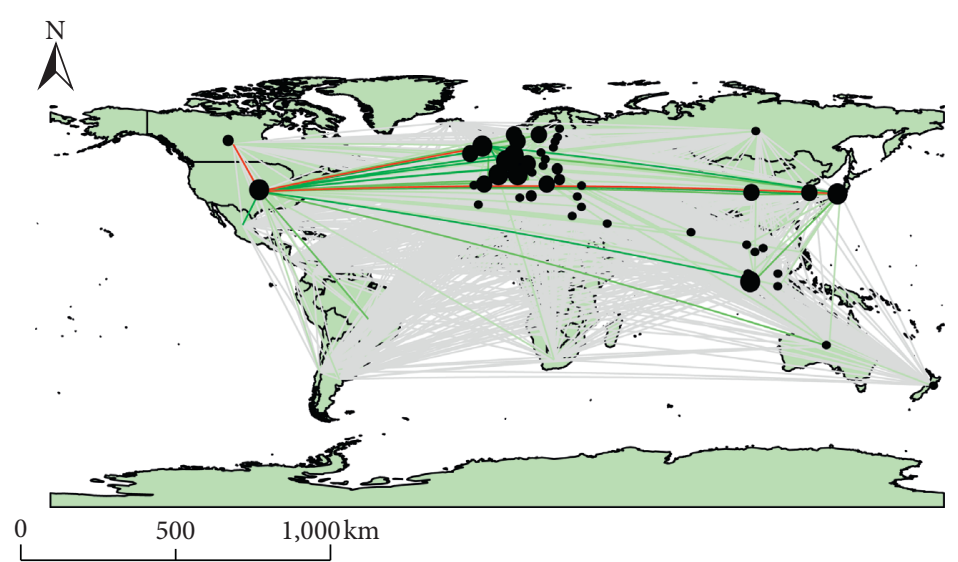

2000 node strength

(Unit: million US dollars)

- 312-10000

- 10000-30000

- 30000-50000

- 50000-100000

- 100000-202737.7
Edge weight
(Unit: million US dollars)

$$
\text { - 600-2500 }
$$$$
\text { - 2500-5500 }
$$$$
\text { - 5500-15000 }
$$$$
\text { - 15000-27637.3 }
$$

(a)

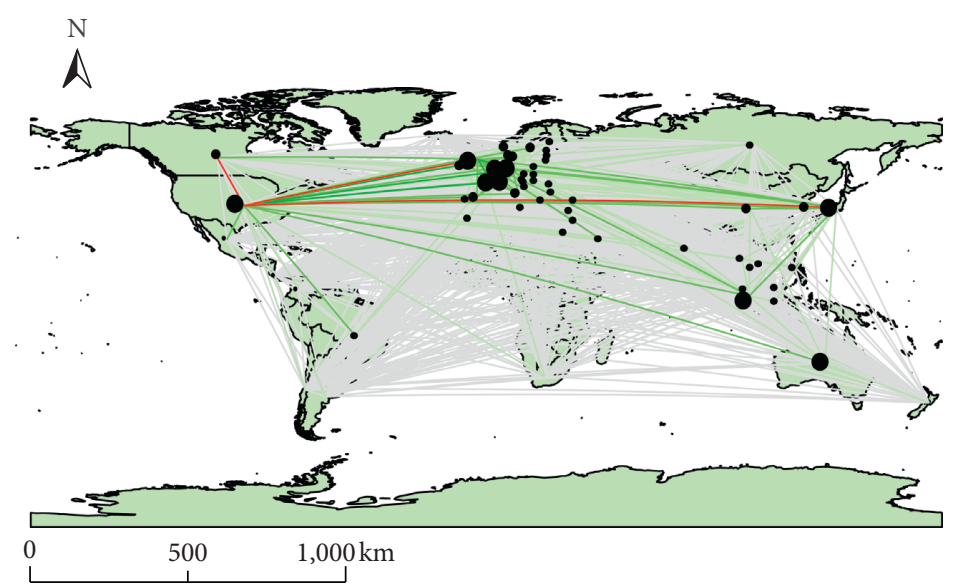

2004 node strength (Unit: million US dollars)

- 292-20000

- 20000-50000

- 50000-100000

- 100000-150000

- 150000-266178.4
Edge weight

(Unit: million US dollars)

$$
\text { 0-800 }
$$

800-3000

- 3000-10000

- 10000-20000

- 20000-38673.9

(b)

FIgure 2: Continued. 


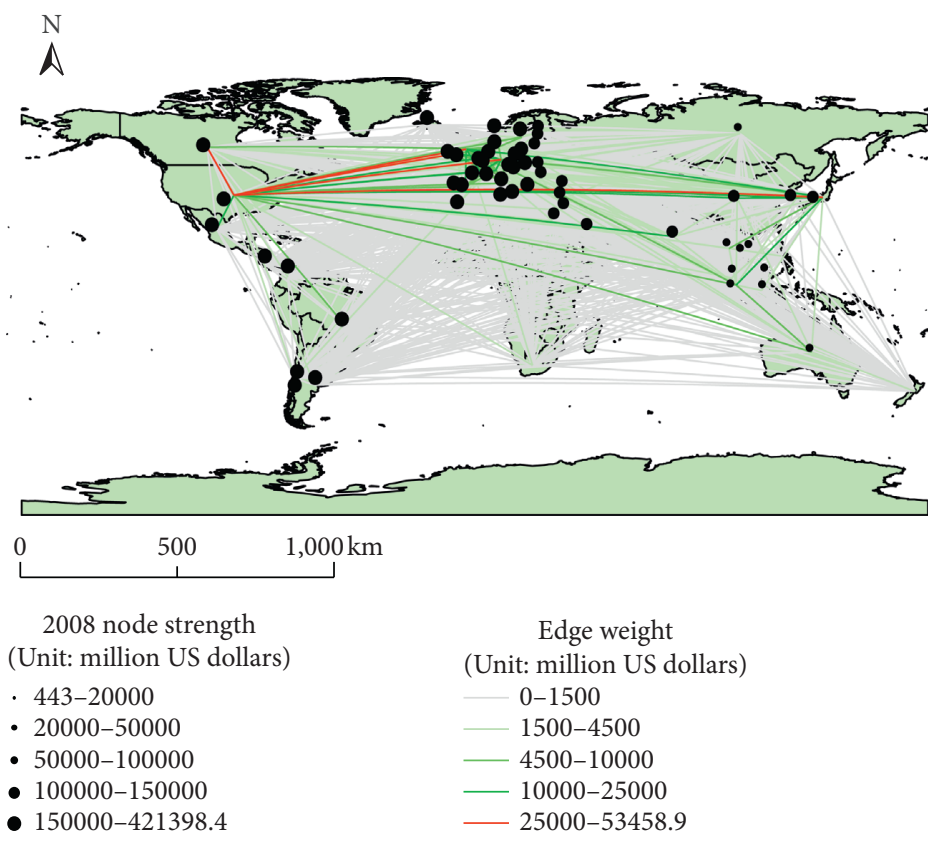

(c)

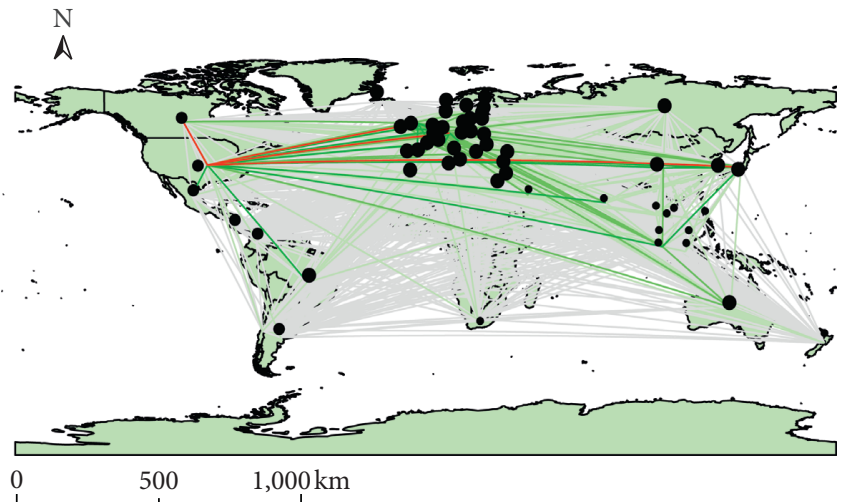

2012 node strength

(Unit: million US dollars)

. 638-40000

- 40000-80000

- 80000-150000

- 150000-250000

- 250000-478035.5
Edge weight

(Unit: million US dollars)

- 0-1000

- 1000-4500

— 4500-10000

- 10000-30000

(d)

FIGURE 2: Spatial structure diagram of the producer services trade network.

China only had strong trade ties with a limited number of countries such as the United States, Japan, and South Korea in 2000. By 2012, these countries were still the closest partners in cooperation with China, while the "triangular trade" of producer services between China, Japan, and South Korea in Asia showed a weakening trend, and Singapore, France, and Germany have become significant trade options.

4.2. Analysis of the Overall Network Topology Characteristics. Then, this paper calculates topology indexes to reflect the overall characteristics of producer services trade network.
In comparison to the changes in network indicators from 2000 to 2012, the following conclusions can be drawn as shown in Table 3: the increase in the number of edges connecting node countries and density shows that the producer services trade network has a tendency of intensification, which is mainly due to the enhanced tradability of service industry in the era of knowledge economy. Network density grew fastest between 2004 and 2008; after 2008, it was relatively stable. The possible reason is that the financial crisis in 2008 has a more significant impact on services trade, and countries have to maintain conservative trade relations to deal with its occurrence. 
TABLE 3: Characteristic statistics of the overall network of producer services trade.

\begin{tabular}{cccccc}
\hline Year & Number of edges & Network density & Average degree & Average path length & Average clustering coefficient \\
\hline 2000 & 509 & 0.28 & 16.68 & 1.74 & 0.55 \\
2004 & 658 & 0.36 & 21.57 & 1.64 & 0.61 \\
2008 & 857 & 0.47 & 28.09 & 1.53 & 0.70 \\
2012 & 892 & 0.49 & 29.25 & 1.51 & 0.71 \\
\hline
\end{tabular}

The upward momentum of the average degree suggests that the connectivity of the network is enhanced. In 2000, the average path length was close to 2 , and each pair of countries with trade needs to establish an indirect relationship through another country. After 2000, the average path length shortened; more and more producer services products can arrive without passing through transit nodes, saving time and transportation costs, and improving the efficiency of trade transactions.

The average clustering coefficient has been rising from 2000 to 2012, which indicates that the producer services trade network had a more obvious phenomenon of trade clusters. Generally speaking, compared with random network with the same number of nodes and edges, a small world network has a smaller average path length and a larger average clustering coefficient [43]. Because the average path length of producer services trade network is in the range of $1.51-1.74$, which is slightly lower than the theoretical value of the random network of the same scale (1.78-2.14), and the average clustering coefficient is in the range of $0.55-0.71$, which is much higher than the average clustering coefficient of the random network $(0.13-0.24)$, it can be considered that this network is a small world network, that is to say, the producer services trade network exhibits the aggregation features of a few nodes as the core; these nodes have a high number of connections, while most other nodes only have fewer connections [44].

\subsection{Network Centrality Analysis}

4.3.1. Centrality of the Unweighted Network. This paper calculates the centrality indicators of all sample countries to explore the individual characteristics of nodes, and then uses Arcgis10.4 for data visualization. Due to space constraints, the top 15 countries and values in 2000 and 2012 are shown in Table 4. In addition, we study the status of countries in the network according to their rankings.

The evolution of centrality index of producer services trade network is shown in Table 4 and Figure 3. The degree centrality of a node represents the number of trade relations and it is the simplest indicator to evaluate its position in the trade network; the results indicate that the top three key nodes are stable in the United States (USA), the United Kingdom (GBR), and Germany (DEU). Due to the lack of location advantages and breakthrough technology, some countries had limited ability to participate in the specialized division, resulting in weaker producer services trade attractiveness, such as Cambodia (CAM) and Costa Rica (CRC), which had the lowest degree centrality. Regarding spatial layout, among the top 15 countries, in 2000, there were 2 in North America, 9 in Europe, and 4 in Asia. In 2012, Asian countries increased to 5, North American countries decreased to 1 , and the number of European countries remained unchanged. With the development of service outsourcing as a new mode of service trade, developing countries have increased investment in communication, computer and information services, and actively undertaken the outsourcing business of developed countries. China $(\mathrm{CHN})$, India (IND), and other countries have gradually become regional or global service outsourcing centers. In particular, benefited from the high concentration of services trade, India showed a trend of long-term rapid growth, making its degree centrality increase significantly. Constrained by the economic slowdown brought by the financial crisis, the activity of producer services trade in developed regions has decreased, resulting in the decline of the average annual growth rate of degree centrality of countries in Europe and American, which are located at the core of the network. But on the whole, the degree centrality of developed countries is still higher than that of the developing countries; developed economies generally have stronger international competitiveness in producer services trade.

The closeness centrality is used to characterize the ability to be "not controlled by other countries." Due to the high degree of trade facilitation and the less dependence on other countries to establish trade relations, countries in the central position, such as the United States and the United Kingdom, usually had higher closeness centrality. The existence of these countries played a vital role in the spatial flow of industrial resources and they acted as the resource "connectors" in the trade network. Conversely, countries that needed more steps or intermediaries to establish trade relations had lower closeness centrality, such as Cambodia and Brunei (BRU). These countries had low efficiency in connecting with other countries and found it difficult to gain spatial advantages.

The betweenness centrality measures the node's ability to control other nodes. The higher the degree, the more the node can serve as a "bridge" in the network. The United States, the United Kingdom, and Germany were still at the forefront; they played an important "intermediary" role and transit capacity in producer services trade network and controlled the links between other countries. The node with the fastest growth in betweenness centrality was Luxembourg, with an average annual growth rate of $48.2 \%$, which may be related to its highly developed finance, insurance services and securities market. As a financial center, a number of service enterprises have formed an outstanding service network. However, emerging economies such as 
TABle 4: Centrality analysis of the producer services trade network (Top 15).

\begin{tabular}{|c|c|c|c|c|c|c|c|c|c|c|c|c|}
\hline \multirow{3}{*}{ Rank } & \multicolumn{6}{|c|}{2000} & \multicolumn{6}{|c|}{2012} \\
\hline & \multicolumn{2}{|c|}{ Degree centrality } & \multicolumn{2}{|c|}{$\begin{array}{l}\text { Closeness } \\
\text { centrality }\end{array}$} & \multicolumn{2}{|c|}{$\begin{array}{c}\text { Betweenness } \\
\text { centrality }\end{array}$} & \multicolumn{2}{|c|}{ Degree centrality } & \multicolumn{2}{|c|}{$\begin{array}{l}\text { Closeness } \\
\text { centrality }\end{array}$} & \multicolumn{2}{|c|}{$\begin{array}{c}\text { Betweenness } \\
\text { centrality }\end{array}$} \\
\hline & Country & Value & Country & Value & Country & Value & Country & Value & Country & Value & Country & Value \\
\hline 1 & USA & 98.33 & USA & 98.36 & USA & 26.62 & USA & 100.00 & USA & 100.00 & USA & 10.75 \\
\hline 2 & $\mathrm{DEU}$ & 85.00 & $\mathrm{DEU}$ & 86.96 & GBR & 10.39 & GBR & 95.00 & GBR & 95.24 & GBR & 4.78 \\
\hline 3 & GBR & 80.00 & GBR & 83.33 & JPN & 7.21 & $\mathrm{DEU}$ & 93.33 & $\mathrm{DEU}$ & 93.75 & DEU & 4.05 \\
\hline 4 & JPN & 75.00 & JPN & 80.00 & ITA & 6.26 & FRA & 88.33 & FRA & 89.55 & FRA & 3.10 \\
\hline 5 & FRA & 68.33 & FRA & 75.95 & AUT & 4.20 & NLD & 86.67 & NLD & 88.24 & JPN & 2.93 \\
\hline 6 & ITA & 65.00 & ITA & 74.07 & CAN & 3.97 & SUI & 85.00 & SUI & 86.96 & NLD & 2.76 \\
\hline 7 & NLD & 61.67 & NLD & 72.29 & FRA & 3.57 & JPN & 81.67 & JPN & 84.51 & SIN & 2.60 \\
\hline 8 & SUI & 61.67 & SUI & 72.29 & $\mathrm{CHN}$ & 2.72 & ITA & 81.67 & ITA & 84.51 & SUI & 2.50 \\
\hline 9 & SIN & 55.00 & SIN & 68.18 & SIN & 2.07 & DNK & 80.00 & DNK & 83.33 & ITA & 2.35 \\
\hline 10 & DNK & 51.67 & DNK & 67.42 & SUI & 1.69 & SIN & 78.33 & SIN & 82.19 & DNK & 2.04 \\
\hline 11 & ESP & 50.00 & ESP & 65.93 & IND & 1.60 & BEL & 78.33 & BEL & 82.19 & KOR & 1.97 \\
\hline 12 & $\mathrm{CHN}$ & 45.00 & $\mathrm{CHN}$ & 64.52 & BEL & 1.27 & KOR & 78.33 & KOR & 82.19 & BEL & 1.81 \\
\hline 13 & KOR & 45.00 & KOR & 64.52 & KOR & 0.98 & $\mathrm{CHN}$ & 76.67 & $\mathrm{CHN}$ & 81.08 & $\mathrm{CHN}$ & 1.27 \\
\hline 14 & CAN & 43.33 & CAN & 63.83 & BRA & 0.98 & SWE & 71.67 & SWE & 77.92 & AUT & 1.01 \\
\hline 15 & BEL & 40.00 & BEL & 61.86 & DEU & 0.62 & IND & 70.00 & IND & 76.92 & SWE & 0.98 \\
\hline
\end{tabular}

India, China had relatively small betweenness centrality, indicating that they do not yet have the same industrial advantages and control power as European and American countries. In 2000, there were 25 countries whose betweenness centrality value was 0 , and it was reduced to 12 countries in 2012; the intermediary capacity of each country in producer services trade network still has excellent disparity, which is an alternative expression of the dependence between trade supply and demand countries.

4.3.2. Centrality of the Weighted Network. In order to show more clearly the changes in trade flow and volume over the long term, a $61 * 61$ relationship matrix was constructed for the weighted and directed network of producer services trade in 2000 and 2012. The rows of the matrix represent the importing country, the columns show the exporting country, and the cells suggest the trade flow from column nodes to row nodes.

Figure 4 shows the export heat map of producer services trade. The shades of color represent the export volume of producer services trade products of various countries. The larger the export volume, the darker the color. Comparing the export heat maps of 2000 and 2012, we can find that orange cells are more densely distributed, which suggests that the interaction between trade entities and the breadth of trade flow are gradually enhanced. However, both heat maps are dominated by light blue cells; it can be found that although the trade volume in this stage has increased significantly, countries with weak trade exchanges of producer services products still have a considerably large proportion, shaping "center-remoteness" block matrix feature. The United States, Germany, the United Kingdom, Japan, Singapore, and other countries with frequent trade contacts form the internal network of the central countries. From the color change of cells, the trade interaction between the central group countries was significantly raised in 2012, while the density of trade flow between central countries and external countries, as well as within external countries, was relatively small. This may be because the radiation and driving force of the countries located in the central plate is relatively limited, and the industrial foundation of the marginal countries is weak So, it is difficult to form deep integration in a short time.

Furthermore, we use the node strength to discuss the centrality features in weighted network. Among them, the out-strength and in-strength are expressed by the weighted out-degree and weighted in-degree of the node, respectively.

Figure 5 describes the changes in the out-strength of various countries. From 2000 to 2012, the export value of producer services trade showed a rapid growth trend; the United States, the United Kingdom, and Germany were in the first echelon of out-strength ranking. The advanced production system and economic strength determined the competitiveness and attractiveness of these countries. From the perspective of spatial distribution, the countries with higher out-strength were mainly concentrated in the European region. Countries such as France, the Netherlands, and Switzerland had strong supply capacity of producer services products. Tunisia in Africa, Brunei and Cambodia in Southeast Asia were the main low out-strength countries. Japan and Singapore were in the leading position of Asia in the network. In 2000, the range of out-strength was 114,366 million U.S. dollars, and in 2012 it rose to 275,008 million U.S. dollars. This indicates that there is spatial polarization in the network, and the Matthew effect of the export of producer services is prominent.

Emerging economies such as China and India have gradually increased their ability to participate in producer services trade. India is the country with the fastest growth in out-strength, with an annual growth rate of $18.82 \%$. From 2000 to 2012, China's out-strength increased from $22^{\text {nd }}$ to $14^{\text {th }}$; the reason is that China has considerable advantages in many emerging markets such as foreign labor export 


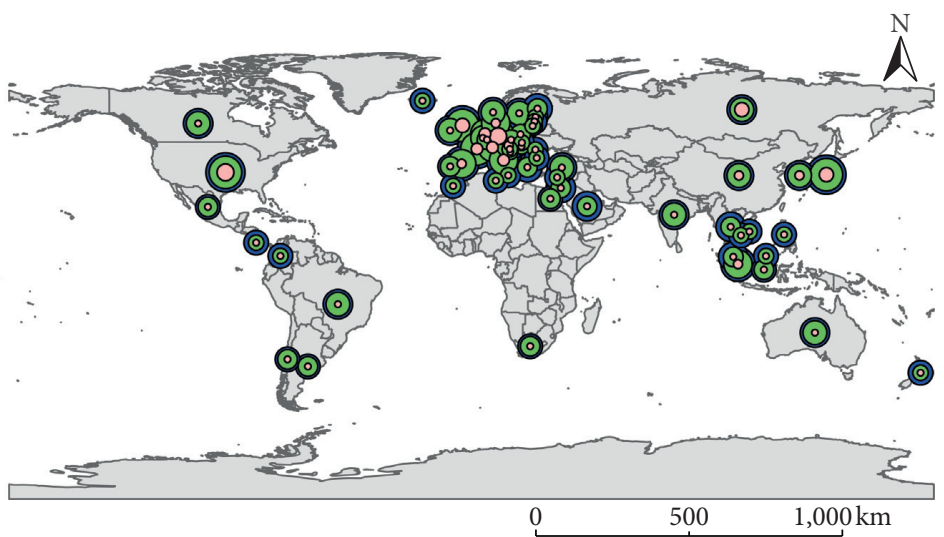

2000 node centrality

Betweenness centrality

- $0-0.5$

○ $0.5-2$

○ $2-4$

O $4-10$

O $10-26.62$

Degree centrality

$$
\begin{array}{ll}
\text { - } & 1.67-13 \\
\circ & 13-28 \\
\circ & 28-45 \\
\text { ○ } & 45-68
\end{array}
$$

O 68-98.33

(a)

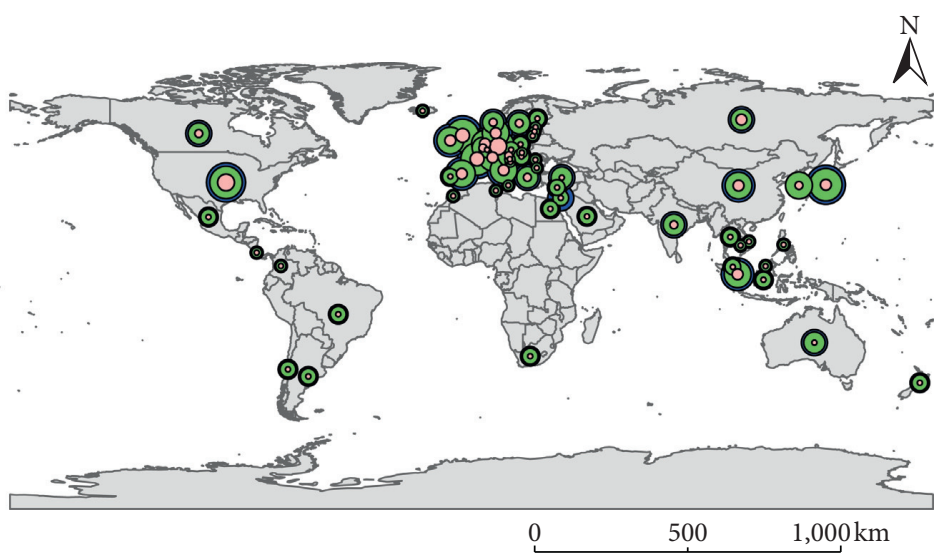

2004 node centrality Betweenness centrality

- $0-0.2$

- $0.2-0.9$

○ $0.9-4$

○ $4-8$

O 8-18.07
- 37-98

- $37.98-55$

- 55-65

○ 65-75

O $75-98.36$
Closeness centrality
Degree centrality

- 1.67-18

- 18-35

○ 35-55

○ 55-75

○ 75-100

(b) 

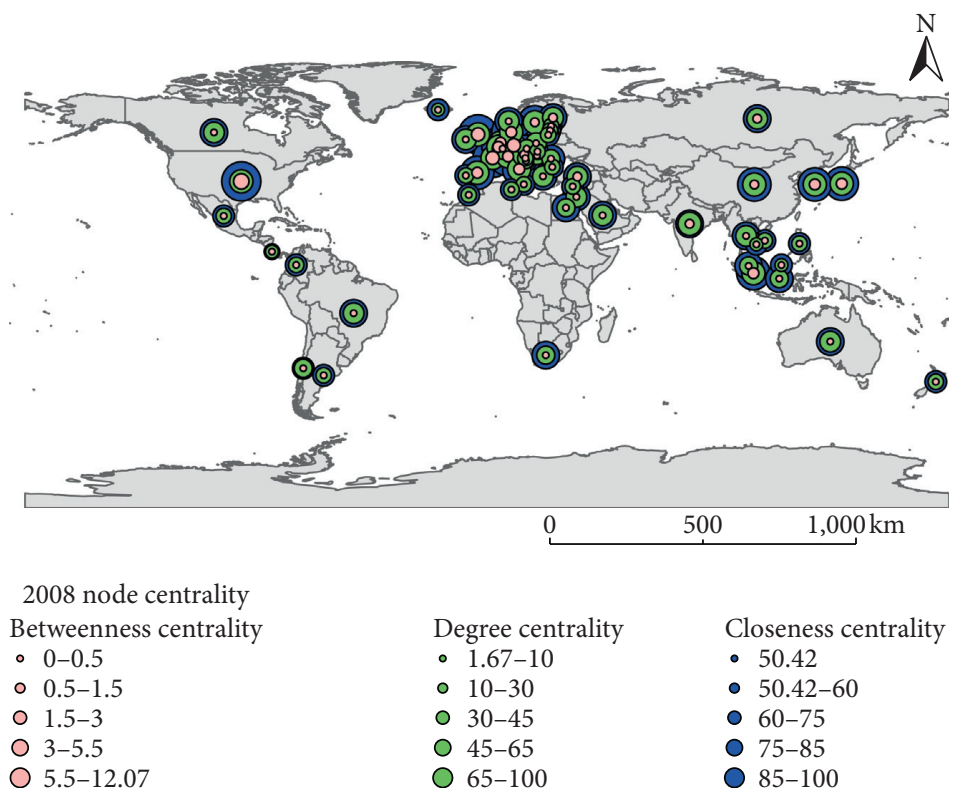

$\begin{array}{ll}\text { Degree centrality } & \text { Closeness centrality } \\ \circ 1.67-10 & \text { ○ } 50.42 \\ \circ 10-30 & \text { ○ } 50.42-60 \\ \circ 30-45 & \text { ○ } 60-75 \\ \circ 45-65 & \bigcirc 75-85 \\ \bigcirc 65-100 & \bigcirc 85-100\end{array}$

(c)
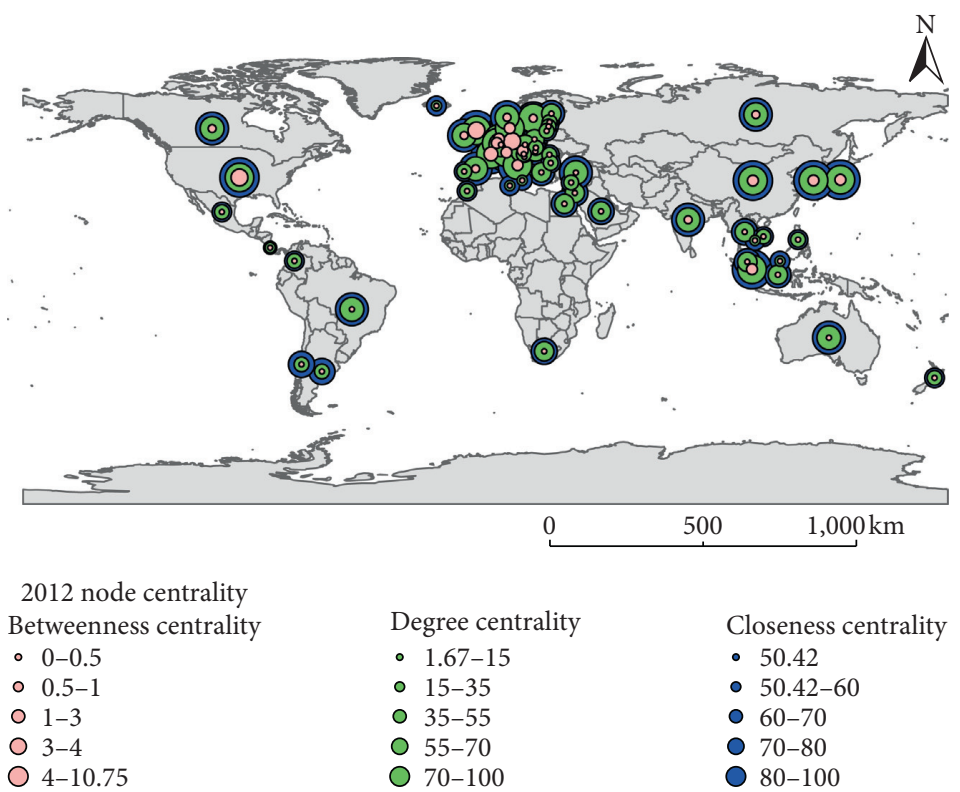

$$
\begin{array}{ll}
\text { Degree centrality } \\
\text { - } 1.67-15 \\
\text { } 15-35 \\
\text { ○ } 35-55 \\
\text { ○ } 55-70 \\
\text { ○ } 70-100
\end{array}
$$

Closeness centrality

- 50.42

- $50.42-60$

- $60-70$

$70-80$

(d)

FIGURE 3: The evolution of centrality of the producer services trade network.

(including engineering), international tourism, transportation and logistics, which is the main direction of service trade export. As a result of the negative effect of the global financial crisis, the average annual growth rate of the outstrength of primary countries declined from 2008 to 2012, and even the out-strength index of the United Kingdom, Italy, Sweden, and other countries that were greatly affected did not increase but decreased in 2012.

Figure 6 shows the modification of the in-strength of producer services trade network. Since the influence of weight on node strength is considered, the importance of some countries has gradually improved with the increase of trade flows, such as India and China, but the performance is relatively different. India is driven by a large number of exports, while China is mainly pulled by the growth of imports. It can be said that India's out-strength effect is more potent than its in-strength effect, while China's is on the contrary, which may depend on the fact that China is a typical producer services consumption country and has a high degree of external dependence. China's weight in-degree increased from the $16^{\text {th }}$ in 2000 to the $4^{\text {th }}$ in 2012. It was the fastestgrowing country in the sample, with an average annual growth rate of $19.38 \%$. Among them, the United States, Japan, South Korea were the primary sources of imports.

Due to the lack of information technology and human capital, as well as the obstacles of opening-up level and 

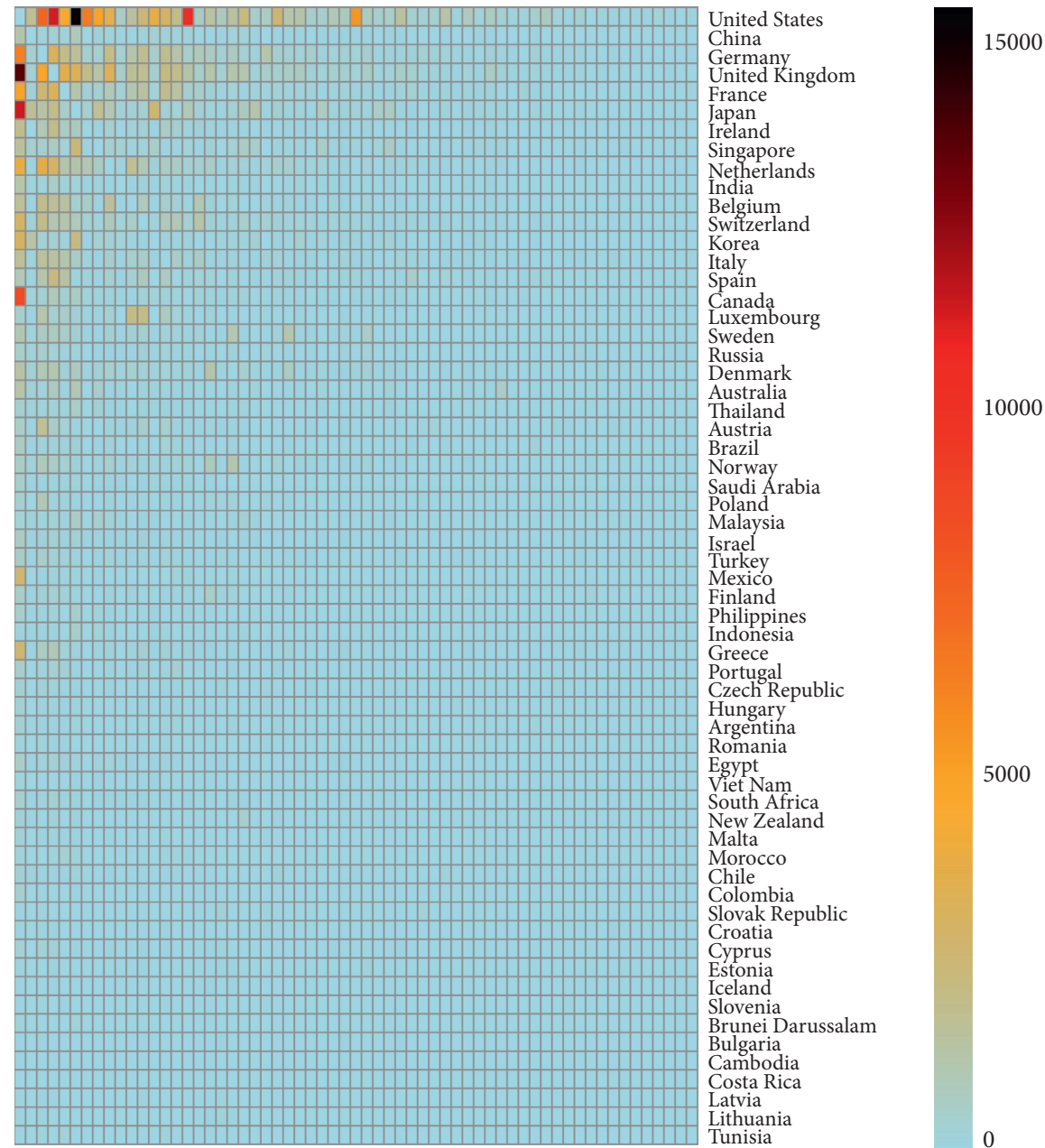

(a)

FIgure 4: Continued. 


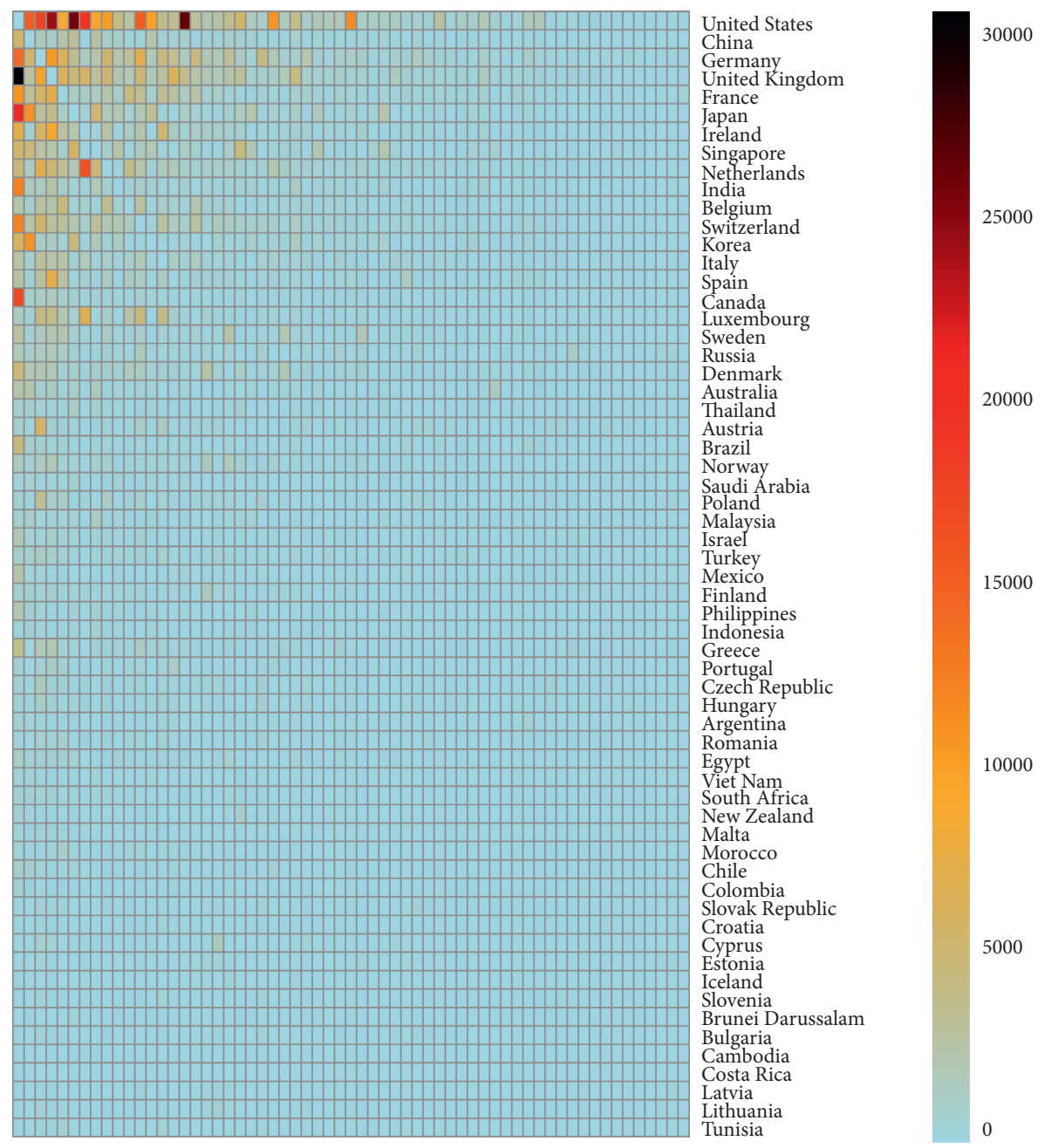

(b)

Figure 4: Export heat map of producer services trade. (a) 2000; (b) 2012.

management organization, the out-strength and in-strength of Eastern European countries such as Estonia, Lithuania, and Latvia, as well as the southern European countries such as Bulgaria and Croatia remained weak. So, they had only low comprehensive influence. Further, the in-strength shows the Matthew effect of increasing range, which is the same as that of out-strength.

Compared with the centrality analysis in the unweighted network to explore which countries have a wider trade scope and greater control over resources and information, the centrality index in the weighted network, node strength, considers more deeply the impact of trade volume on the status of countries in the network. Typically, several emerging developing economies have not shown remarkable core power in the unweighted network, but their position in the weighted network has risen significantly due to the consideration of trade scale. Integrating the centrality research results of the two kinds of networks, we found that there is a strong positive correlation between them; countries with more trading partners tend to have higher trade strength. For instance, countries such as the United States, the United Kingdom, and Germany with higher node centrality indicators in the unweighted network are consistent with countries with upper node strength in the weighted network; these countries have both extensive trade links and substantial foreign trade. The reason lies in that the developed countries have a solid base of producer services and provide comprehensive policy support for producer services trade. Under their competitive advantages in knowledge-intensive and technology-intensive services industries, they can choose more trade target countries and generate massive trade flows, thus becoming a powerful producer services trade country.

\section{Cohesive Subgroup Analysis and Core- periphery Structure Analysis}

5.1. Cohesive Subgroup Analysis. In the formation process of producer services trade network, the trade entities will conform subgroups due to the affinity of trade relations. Therefore, referring to Wang's research method [45], considering that the subgroup division is more robust after long- 


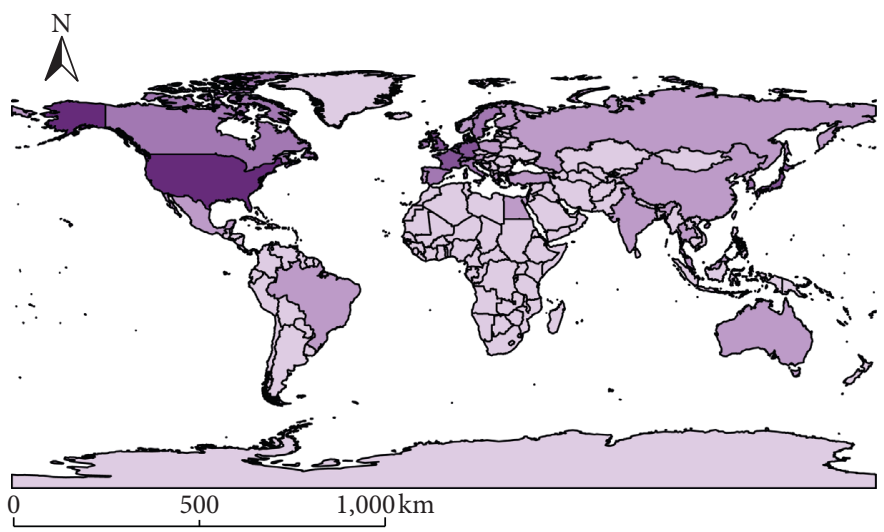

2000 weighted out-degree

(Unit: million us dollars)
0-1853.6
$1853.6-7439.7$
18017-56459.8
56459.8-114424.1

7439.7-18017.1

(a)

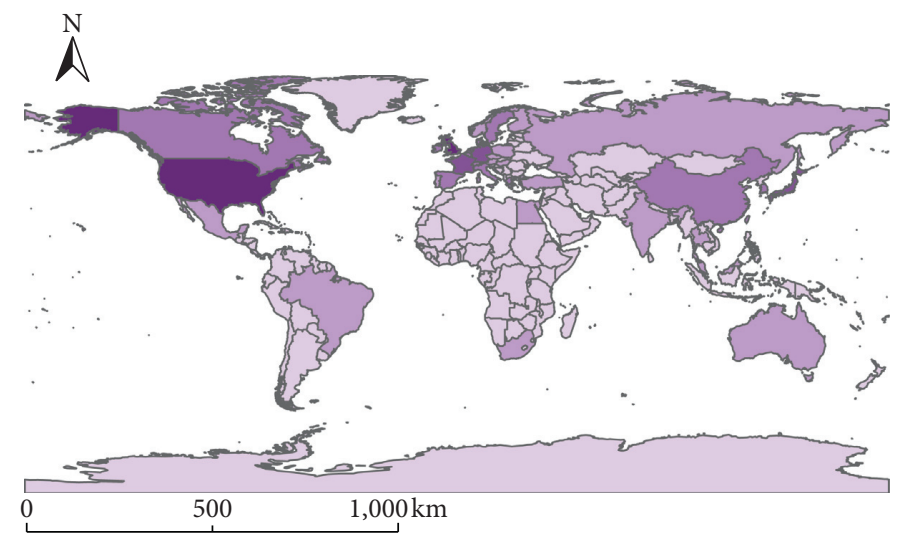

2004 weighted out-degree

(Unit: million us dollars)

$\square$ 0-2717.9
$\square \quad 2717.9-11369.5$
$\square \quad 11369.5-29921.8$

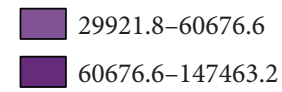

(b)

Figure 5: Continued. 


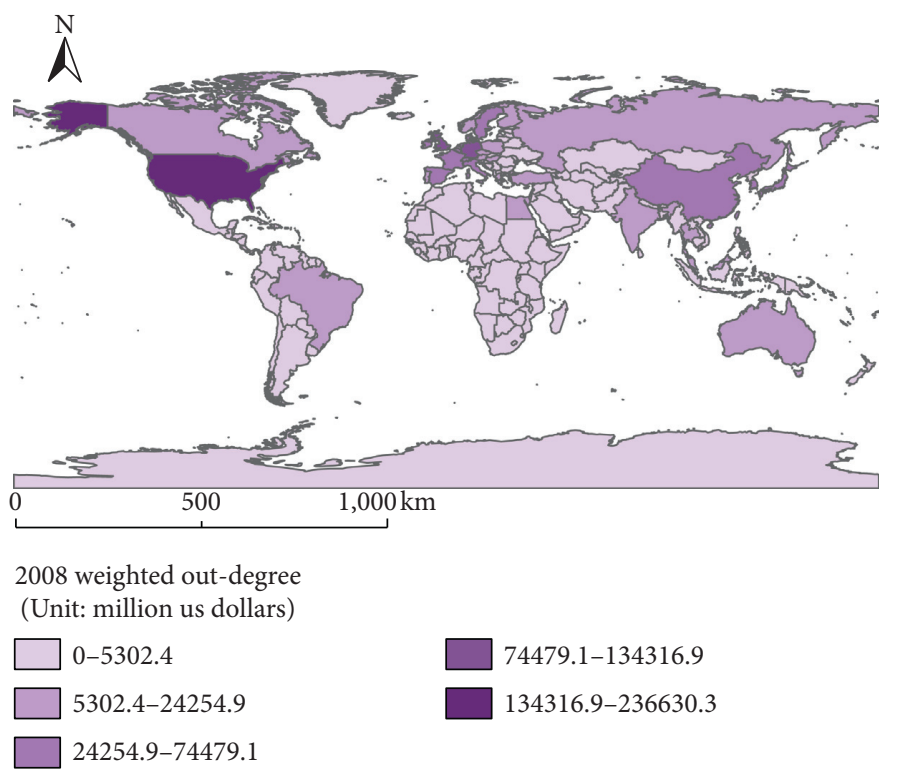

(c)

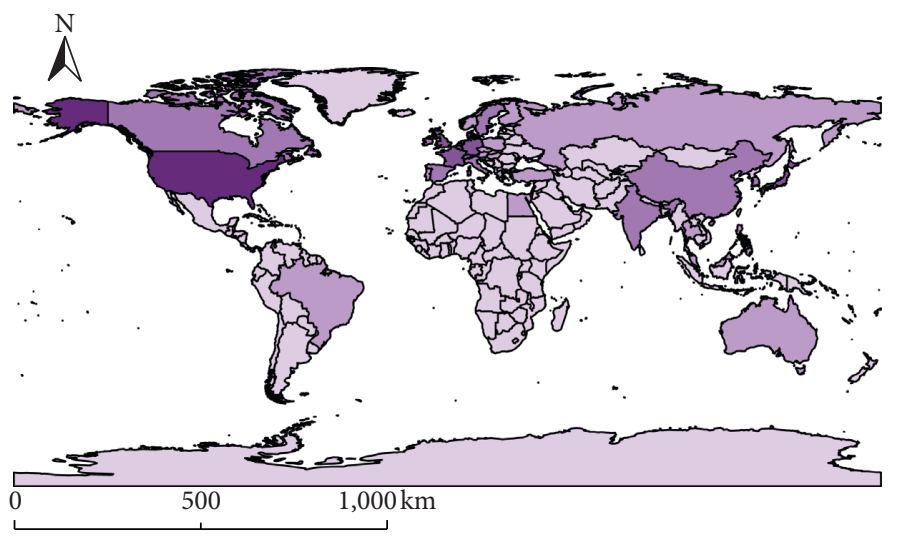

2012 weighted out-degree

(Unit: million us dollars)

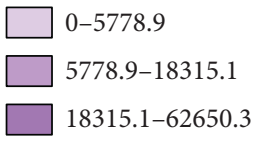

$62650.3-129917.0$

$129917.0-275206.3$

(d)

Figure 5: Out-strength spatial distribution of the weighted and directed network.

term development, this paper selects 2000 and 2012 as the representative years, and uses the CONCOR algorithm to carry out cohesive subgroup analysis, so as to determine the number of subgroups and the members included in them, and explore the spatial spillover relationship, with the purpose of studying the evolution of producer services trade network from the perspective of subgroup structure.

The calculation results show that the producer services trade network has cohesive subgroup structure, and the classification of cohesive subgroups is not strictly based on the economic level. According to Figure 7(a), the producer services trade network in 2000 was divided into four subgroups, of which subgroup I was represented by the United States, Netherlands, and the United Kingdom. This subgroup was agglomerated by the attraction of economic strength to form an American and European community composed of 13 countries. Subgroup II had the most enormous scale. Due to geopolitical and cultural factors, it had formed an Asia-Europe association represented by China, India, including 29 Asian, European, and African countries such as South Korea and Singapore. Subgroup III was represented by Hungary, including 15 European and South American countries such as Czech and Chile. Subgroup IV was an independent community consisting of Croatia, Cambodia, Bulgaria, and Lithuania. Shown by Figure $7(\mathrm{~b})$, the number of subgroups did not change in 2012, but the community differentiation within the subgroups was modified. China, South Korea, and other rapidly 


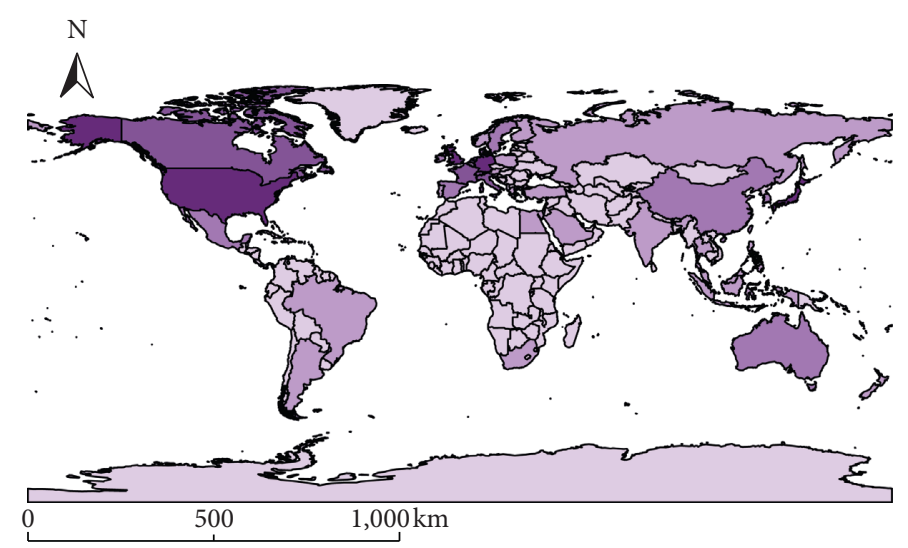

2012 weighted in-degree

(Unit: million us dollars)

$\square$ 0-1858.9
$\square$ 1858.9-6497.9
$\square$ 6497.9-13903.4

(a)

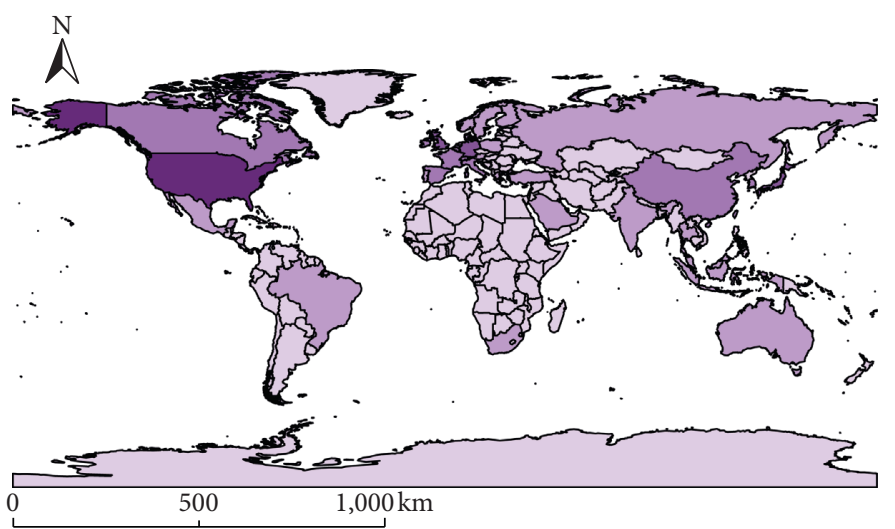

2004 weighted in-degree

(Unit: million us dollars)
0-3615.2
3615.2-15962.1
15962.1-39822.3

$39822.2-72317.6$

72317.6-118711.5

(b)

Figure 6: Continued. 


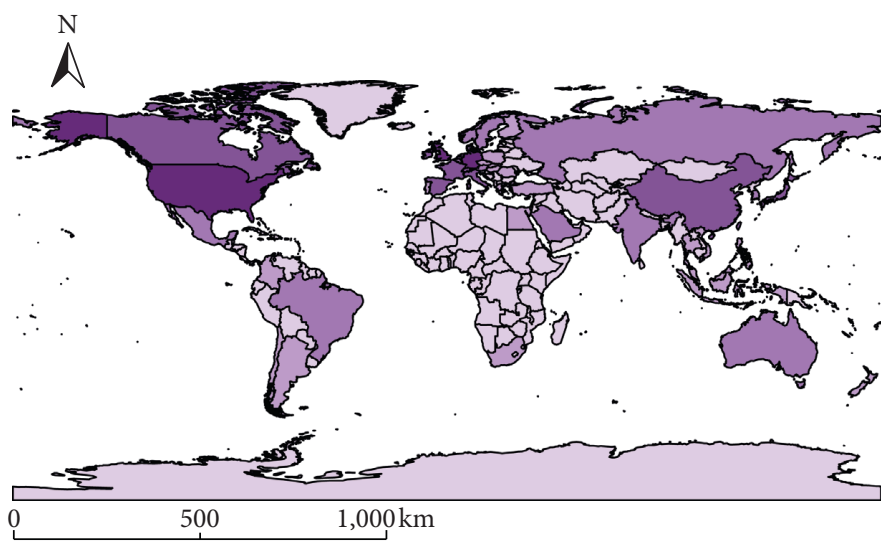

2008 weighted in-degree (Unit: million us dollars)

$\begin{array}{ll}\square \text { 0-2658.5 } & \square 32585.7-67251.5 \\ \square \text { 2658.5-12758.4 } & \square \text { 67251.5-184768.1 }\end{array}$

(c)

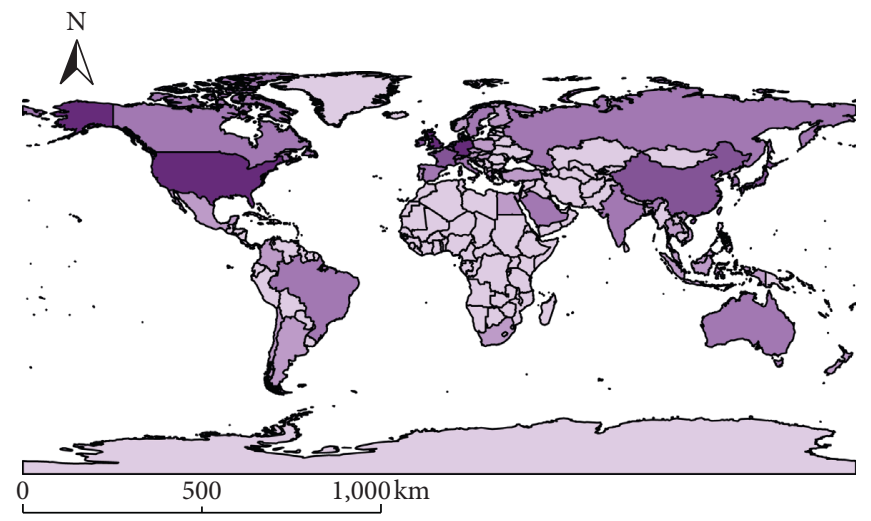

2012 weighted in-degree (Unit: million us dollars)
$0-4584.6$
4584.6-18066.4
$18066.4-45924.1$

$45924.1-81612.6$

$81612.6-202829.2$

(d)

FIGURE 6: In-strength spatial distribution of the weighted and directed network.

developing Asian countries entered subgroup I from subgroup II, and integrated with developed countries into a community. Subgroup II was still the community with the largest number of members. The close geographical distance made Croatia and Bulgaria enter subgroup III from subgroup IV; thus, subgroup III became an association with southern European countries as its main members, while the subgroup belonging to other major countries in the world, such as Russia and Canada, had little change. Countries such as the United States, Germany, the United Kingdom, France, and Japan were all in the same subgroup in 2000 and 2012; these countries tend to choose each other based on the principle of reciprocity and have stronger condensation effect compared with trade linkages among other countries.
Table 5 shows the spatial spillover relationship between cohesive subgroups, and the value of the diagonal of the density matrix reflects the density of the internal association of the subgroups. In 2000, the density value within subgroup I was the largest, the trade ties among the member states in the plate were relatively sufficient, and subgroup I had a distinctive feature of reflexivity. The reason is that subgroup I, including the United States, Germany, the United Kingdom, and other traditional powers of producer services trade, can exert significant influence on trade by making use of location attraction and industry advantages. In addition, subgroup I had a strong spillover effect on subgroup II, and the import of producer services trade of subgroup II mainly came from 


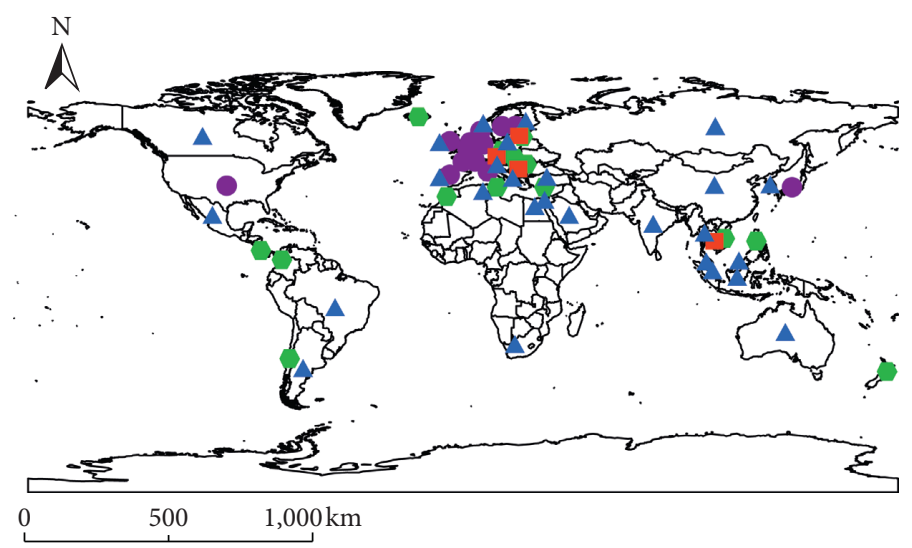

$\begin{array}{ll}2000 \text { cohsive subgroups } & \\ \text { - Subgroups I } & \text { Subgroups III } \\ \text { - Subgroups II } & \text { Subgroups IV }\end{array}$

(a)

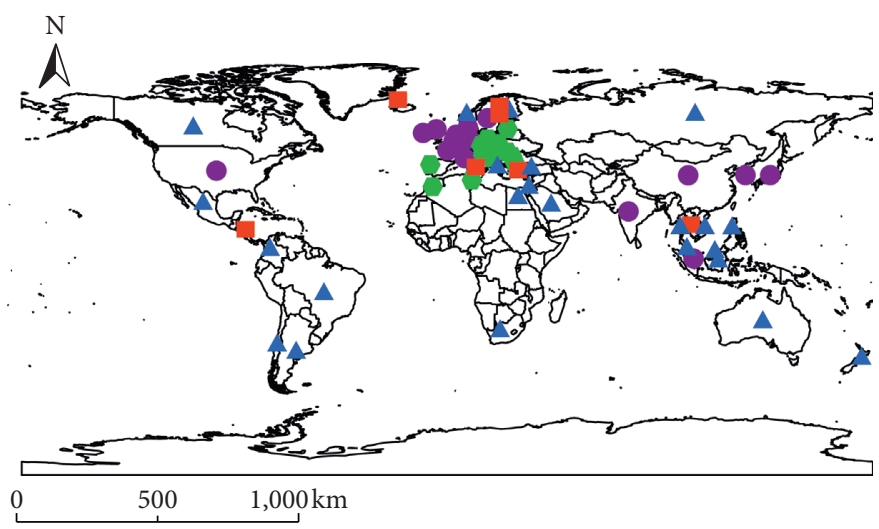

2012 cohsive subgroups

- Subgroups I

Subgroups III

A Subgroups II

- Subgroups IV

(b)

Figure 7: Cohesive subgroups of the producer services trade network in 2000 and 2012.

TABle 5: Density matrix of cohesive subgroups of the producer services trade network.

\begin{tabular}{lccccccccc}
\hline & \multicolumn{3}{c}{2000} & & & & \multicolumn{2}{c}{2012} & \\
I & II & III & IV & & I & II & III \\
\hline I & 0.833 & 0.515 & 0.144 & 0.000 & I & 0.980 & 0.797 & 0.427 & 0.103 \\
II & 0.509 & 0.081 & 0.028 & 0.000 & II & 0.652 & 0.190 & 0.033 & 0.043 \\
III & 0.149 & 0.021 & 0.010 & 0.000 & III & 0.491 & 0.054 & 0.244 & 0.011 \\
IV & 0.000 & 0.009 & 0.000 & 0.000 & IV & 0.183 & 0.037 & 0.022 & 0.048 \\
\hline
\end{tabular}

subgroup I. Subgroup II also had spillover effect on subgroup I, while the internal relationship was weak. Subgroup III only had fairly sparse trade relationship with subgroup I, and subgroup IV even did not have any acceptance or sending links with other subgroups. In 2000, both subgroup III and subgroup IV were in an extremely isolated position in the network. It can also be seen that the radiation effect of subgroup I on subgroup III and subgroup IV was still less, and the whole network was in a very unbalanced development stage.
In 2012, the density coefficient did not appear to a value of 0 , and the values in the density matrix were all greater than those in 2000, indicating that the correlation between and within each subgroup was closer than that in 2000 . Subgroup I was still in the plate with the closest internal trade connection, and it not only had significant spillover effect on subgroup II and subgroup III but also had a stimulating effect on the trade development of subgroup IV. From the point of view of the relationship between subgroups, subgroup II and subgroup I had the closest trade 
relations, and the economies within these subgroups enhanced each other's influence through stable trade cooperation. Subgroup III also had spillover effect on subgroup I, and the internal trade linkage strength had been dramatically improved. This may be benefited by the evolution of subgroup III into a Southern European community in 2012, and the spatial proximity made the trade cooperation within the subgroup more intimate. However, the trade relationship between subgroup IV and other subgroups was still fairly sparse, making it difficult for each subgroup in the trade network to form a closed transmission mechanism in space. The subgroup agglomerated by countries with powerful economic forces (the United States, the United Kingdom, etc.) had radiative impact on both the inner and outer subgroups, which can be considered as an obvious two-way spillover effect, while the members who were in the position of the orphan depend on the supply from that subgroup.

5.2. Core-Periphery Structure Analysis. The core-periphery structure analyzes the spatial pattern evolution from the perspective of the network secondary structure. Chen Yinfei pointed out that the world economic structure can be divided into three levels, namely, the core layer, the semiperiphery layer, and the periphery layer. It is believed that the countries with the core degree greater than 0.1 are located in the core layer, countries with core degree greater than 0.01 but less than 0.1 are in the semi-periphery layer, and countries with core degree less than 0.01 are in the periphery layer [46]. Compared with other indexes, the core degree can directly reflect the national status and spatial hierarchy structure of the network. Most notably, the centrality and core degree are not necessarily the same; the centrality index reflects the growth of trade link and volume between countries, while the core country refers to the part of the subjects with strong interaction in the countries with high centrality. In the case of the lack of linkages between actors with high centrality, their core degree may be low.

As can be seen from Table 6, there is a "core-semi-periphery-periphery" structure in producer services trade network, but the number and members of each layer change, resulting in the reorganization of the hierarchical structure. The number of core layer countries only increased significantly in 2004, showing an inverted U-shaped trend of first rising and then falling. Most of the countries were in the semi-periphery areas, while the number of periphery countries has significantly increased from 2000 to 2012. The possible reason for this phenomenon is that the core countries are mainly developed countries, which have the right to speak and formulate rules of producer services trade. In order to maximize their own interests, many trade agreements have been signed. However, the existing rules have not adequately solved the problem of trade liberalization. Instead, the different preferential treatment and origin rules of each agreement are intertwined to form the "spaghetti bowl" effect, leading to the marginalization of some underdeveloped countries. As the trade network is supported by fewer core countries and semi-periphery countries, the control power has slightly decreased, which makes the network vulnerable, necessitating its structure to be optimized and improved

The results in Table 7 show that the core degree of each country fluctuated from 2000 to 2012. The top ten countries in the core degree were mainly powerful nations in Western Europe, such as the United Kingdom (GBR), France (FRA), and Netherlands (NLD). Regarding specific changes, the core degree of the United States declined significantly in 2004 and 2012. The reason may be that China's accession to the WTO and the official circulation of Euro increased the core degree of China, Germany, and France, resulting in the core degree of the United States declining for the first time. After the subprime crisis of 2008, the core degree of the United States declined for the second time. The core degrees of European Union (EU) member states, Germany and France, maintained the same change trend from 2000 to 2012. The Euro currency promoted the trade status of member nations, so the core degree of both countries improved greatly in 2004. Due to the impact of the financial crisis, the core degree in 2008 was lower than that in 2004, but after that, their core degree resumed the upward trend with the gradual recovery of the economy. Furthermore, countries with a high degree of centrality such as France and Denmark do not have a high core degree, which verifies the conclusion that the centrality index and core degree are not entirely the same. In terms of emerging economies, the core degree of BRICs member countries, namely, Brazil (0.062 to 0.085 ), China (0.02 to 0.099 ), Russia (0.038 to 0.05 ), and India (0.044 to 0.094$)$, have significantly improved from 2000 to 2012, reflecting the increasing competitiveness and importance of these trading entities and the apparent tendency of diversification of the network.

\section{Analysis of the Influencing Factors of the Producer Service Trade Network}

After exploring the spatial heterogeneity and dynamicity of the producer services trade network, we further use the method of QAP regression to study the determinants of the evolution of network structure. In order to evade the great impact of the financial crisis on the structural changes of producer services trade network, this paper selects 2012, when the market gradually recovers stability and economic growth, and 2000, the first year of the statistical year, for QAP regression analysis. The corresponding matrix of the variables was brought into the regression model; after 2000 random permutations, the QAP regression results of the unweighted network and weighted network (shown in Table 8) are obtained. The models all pass the significance test of $1 \%$.

By comparing the results in Table 8 , it can be found that the estimated coefficient of economic distance was significantly negative in each regression model, indicating that the smaller the difference in economic development level between countries, the more conducive to the generation of trade relations and the increase of trade flows. The reason is that countries with small difference in economic levels have similar consumption structures, which increases the possibility of producer services trade. Trade agreement relations 
Table 6: Number of core, semi-periphery, and periphery countries, 2000-2012.

\begin{tabular}{lcccc}
\hline Year & 2000 & 2004 & 2008 & 2012 \\
\hline Core layer & 12 & 15 & 11 & 12 \\
Semi-periphery layer & 46 & 38 & 42 & 38 \\
Periphery layer & 3 & 8 & 8 & 11 \\
\hline
\end{tabular}

TABLE 7: Core degree of the producer services trade network (Top 10).

\begin{tabular}{|c|c|c|c|c|c|c|c|c|}
\hline \multirow{2}{*}{$\begin{array}{l}\text { Year } \\
\text { Rank }\end{array}$} & \multicolumn{2}{|c|}{2000} & \multicolumn{2}{|c|}{2004} & \multicolumn{2}{|c|}{2008} & \multicolumn{2}{|c|}{2012} \\
\hline & Country & Core & Country & Core & Country & Core & Country & Core \\
\hline 1 & USA & 0.626 & USA & 0.577 & USA & 0.679 & USA & 0.620 \\
\hline 2 & GBR & 0.473 & GBR & 0.410 & GBR & 0.367 & GBR & 0.396 \\
\hline 3 & $\mathrm{DEU}$ & 0.251 & DEU & 0.307 & DEU & 0.256 & DEU & 0.273 \\
\hline 4 & JPN & 0.248 & JPN & 0.268 & JPN & 0.238 & JPN & 0.249 \\
\hline 5 & NLD & 0.198 & CAN & 0.217 & IRL & 0.192 & SUI & 0.211 \\
\hline 6 & SUI & 0.166 & FRA & 0.212 & SUI & 0.185 & IRL & 0.189 \\
\hline 7 & FRA & 0.160 & NLD & 0.196 & KOR & 0.185 & CAN & 0.187 \\
\hline 8 & ITA & 0.148 & SUI & 0.174 & FRA & 0.171 & NLD & 0.184 \\
\hline 9 & BEL & 0.144 & IRL & 0.164 & NLD & 0.169 & FRA & 0.176 \\
\hline 10 & ESP & 0.129 & ESP & 0.135 & IND & 0.152 & SIN & 0.124 \\
\hline
\end{tabular}

TABLE 8: QAP regression result of the producer services trade network.

\begin{tabular}{lcccc}
\hline \multirow{2}{*}{ Variable } & \multicolumn{2}{c}{ Unweighted network } & \multicolumn{2}{c}{ Weighted network } \\
& 2000 & 2012 & $-0.034^{*}$ & $-0.060^{* *}$ \\
\hline Dis_gdp & $-0.041^{*}$ & $-0.062^{*}$ & $0.045^{*}$ & $-0.058^{*}$ \\
Comfta & $0.131^{* * *}$ & 0.026 & -0.037 & $-0.110^{* * *}$ \\
Dis_cap & -0.057 & $-0.144^{* * *}$ & $-0.063^{* * *}$ & $-0.062^{* * *}$ \\
Dis_ins & 0.016 & $0.044^{*}$ & $0.108^{* * *}$ & $0.130^{* * *}$ \\
Comlan & $0.108^{* * *}$ & $0.083^{* * *}$ & $0.178^{* *}$ & $0.172^{* *}$ \\
Dis_tec & $0.261^{* * *}$ & $0.201^{* * *}$ & 0.028 & -0.028 \\
Dis_pop & $0.086^{*}$ & -0.001 & & \\
\hline
\end{tabular}

Notes: ${ }^{* * *}$ represents $p<0.01,{ }^{* *}$ represents $p<0.05,{ }^{*}$ represents $p<0.1$.

had an important positive impact on the trade network in 2000, with common trade agreements facilitating trade exchanges. However, in the 2012 unweighted network, the regression coefficient did not pass the significance test of $1 \%$. In the weighted network, it was significantly negative. The reason may be that the signing of a variety of bilateral and regional services trade agreements has formed the phenomenon of a "spaghetti bowl," and the producer services trade faces greater disputes, which on the contrary inhibits the trade cooperation among countries. The estimated coefficient of geographic distance was not significant in the two networks in 2000. In 2012, it was negative in both the unweighted and weighted network, and has passed the significance test of $1 \%$, which shows that the producer services trade is also affected by geographic distance. This may be related to the fact that some producer services trade relies on goods trade and people's spatial transformation, such as the transportation industry, which is vulnerable to the influence of geographical distance, resulting in spatial proximity changing the structure of trade network. The regression coefficient of institutional distance was not significant in the unweighted network in 2000, but it is positive in 2012, and has passed the significance test of $10 \%$; the institutional difference between the two countries had a certain impact on the establishment of trade ties. However, in the weighted network of 2000 and 2012, the regression coefficient of institutional distance had an extremely remarkable negative effect on trade network, indicating that countries had greater trade volume with partners adjacent to their own systems. This depends on the smaller institutional difference to reduce the distortion of resource allocation and the occurrence of corruption, and the lack of effective institutional guarantee will make international trade prone to friction and disputes. Language relationship had a notable positive impact on the formation of producer services trade network. The reason is that the linguistic homogeneity may mean that they are in the same cultural circle, communication barriers and risks in trade are less, thus it is easier to create trade links, and trade scale is larger than in countries with greater cultural difference. The regression coefficient of technical distance was significantly positive, which was consistent with the research conclusion of Yang Chen, who analyzed the factors influencing the services trade network structure from the perspective of industry heterogeneity. The difference in 
technological level is in favor of the occurrence of new services trade relations such as finance and communication industry [33]. The regression coefficient of population size difference was only positive in the 2000 unweighted network, but not in other networks. It shows that in 2000, countries with large populations tended to establish trade links with small population countries, but they did not significantly increase trade scale. Because the difference of population size cannot directly affect the opening of the service market, this variable has little effect on the changes of producer services trade network.

\section{Discussion and Conclusion}

This paper constructs producer services trade network and explores its spatial heterogeneity and structural evolution. The main contribution lies in the innovative analysis framework of integrating social network and economic geography, deepening the comprehending of network topological function and interaction in producer services trade system, and providing reference for policy-makers to adopt appropriate trade strategies. The leading conclusions are as follows.

Geographically, the producer services trade network has evolved from a dual-core structure of "USA-Western Europe" to the radial mode with the United States as the explosive point. The spatial heterogeneity reflects the imbalance of trade pattern; frequent trade activities are primarily concentrated in developed countries in East Asia, North America, and Western Europe, and the low-value trade agglomeration areas in southern Europe and Southeast Asia are the "depressions" that hinder the process of economic integration. Topologically, the density and average degree of the network have an upward trend, and the phenomenon of small world network is increasingly apparent. The entire network exhibits the structural feature of "core-semi-peripheral-periphery"; Western Europe is a gathering area of core countries, and Japan and the United States have the most principal forces in Asia and North America, respectively. Due to the negative impact of various asymmetric trade agreements, the number of marginal countries continues to increase, which is detrimental to the stable and complete development of the trade network. Thus, we need to consider relative convergence when formulating new and amending trade rules, set comparatively uniform origin rules, eliminate rule overlaps and conflicts, and establish efficient rule implementation and dispute settlement institutions.

The QAP regression analysis shows that this structure evolution of the producer services trade network is often conditioned by trade agreement relations, language relations, and differences in economy, geography, institution, and technology between the two countries. In particular, the language difference and technological distance have greater impact in each model. Therefore, each country still needs to strengthen trade ties with partners in the same cultural circle, unite with similar stakeholders to implement diversified trade market strategies, and cultivate the core technological advantages of domestic producer services to enhance the status of international division of labor.

In terms of competitiveness evaluation, countries with superior centrality and core degree, such as the United States, the United Kingdom, and Germany, have undoubted leading power and sufficient producer services supply capacity, and assume the role of bridges and supporters in the network. China, India, and other emerging economies have benefited from increased node strength and improved their position in the network, but it did not change the trade configuration dominated by developed countries. Due to the high technical threshold, it is difficult for most developing countries to occupy the export market. Therefore, they need to enhance the industrial attraction and competitive advantage through innovation-driven endeavors. For example, relevant enterprises are encouraged to increase the investment of capital, technology, and talents, and establish research and development centers, so as to improve the export quality of producer services trade.

With regard to the system interaction, cohesive subgroup analysis reveals that the producer services trade network has spatial spillover relations; major traditional service trade powers in Europe are condensed in the same subgroup based on the principle of reciprocity, but its radiation and driving power for isolated subgroups is still very small, which is not conducive for the integration of member states into the trade network. Thus, isolated subgroups need to strengthen cooperation with countries with strong spillover effects, import appropriate production factors, and form optimal allocation with domestic resources to stimulate development potential and trade participation, and ultimately establish a mutually beneficial and win-win trading system.

However, this article still has some limitations, which can be further improved and supplemented in future work:

(1) Due to the problem of data availability, the research interval is relatively lagging at this stage. When the data are easy to obtain, we will further analyze the complexity and systematic characteristics of producer services trade network in recent years, especially the impact of trade war and COVID-19 epidemic on the network.

(2) This article is a holistic analysis that integrates the trade data of producer services industries. The next step is to conduct a more detailed study of each subindustry and explore the changes in the trade pattern from multiple industrial dimensions.

(3) At present, this paper still stays at the basic level of the analysis of the characteristics of producer services trade network, without an in-depth theoretical research. In the future, we need to use more complex system theory to explore the dynamic features and evolution mechanism of the trade network.

\section{Data Availability}

The relevant data of this paper can be obtained from the corresponding author. 


\section{Conflicts of Interest}

The authors declare no conflicts of interest.

\section{Acknowledgments}

This research was supported by grant from the National Social Science Foundation of China (Grant No. 17BJY071).

\section{References}

[1] Y. Bi, W. R. J. Alexander, and Z. Pei, "Factors affecting trade in services: evidence from panel data," Applied Economics, vol. 51, no. 34, pp. 3730-3739, 2019.

[2] M. Afzal, S. Shoaib Ahmed, and M. Waseem Shahzad, "Impact of merchandize and services trade on economic growth of Pakistan," Journal of Contemporary Research in Business, Economics and Finance, vol. 1, no. 2, pp. 30-36, 2019.

[3] P. Guerrieri and V. Meliciani, “Technology and international competitiveness: the interdependence between manufacturing and producer services," Structural Change and Economic Dynamics, vol. 16, no. 4, pp. 489-502, 2005.

[4] H. Breinlich, "Producer services and trade liberalization," International Encyclopedia of Geography: People, the Earth, Environment and Technology, pp. 1-9, 2017.

[5] W. J. Coffey, "Producer services research in Canada," The Professional Geographer, vol. 47, no. 1, pp. 74-81, 1995.

[6] S. Illeris, "The role of services in regional and urban development: a reappraisal of our understanding," The Service Industries Journal, vol. 25, no. 4, pp. 447-460, 2005.

[7] Y. Zhao, J. Liu, F. Zhang, and M. Liu, "Research on the spatial distribution pattern of producer service firms in urban Harbin," Proceedings of the ICA, vol. 2, pp. 1-6, 2019.

[8] R. O. Pereira and B. Derudder, "The cities/services-nexus: determinants of the location dynamics of advanced producer services firms in global cities," The Service Industries Journal, vol. 30, no. 12, pp. 2063-2080, 2010.

[9] Y. Wu, P. Fan, and H. You, "Spatial evolution of producer service sectors and its influencing factors in cities: a case study of hangzhou, China," Sustainability-Basel, vol. 10, 2018.

[10] D. Haberly and D. Wójcik, "Regional blocks and imperial legacies: mapping the global offshore fdi network," Economic Geography, vol. 91, no. 3, pp. 251-280, 2015.

[11] Z. Liao, Z. Wang, and K. Guo, "The dynamic evolution of the characteristics of exchange rate risks in countries along "the belt and road" based on network analysis," Plos One, vol. 14, 2019.

[12] H. Li, H. An, W. Fang, Y. Wang, W. Zhong, and L. Yan, "Global energy investment structure from the energy stock market perspective based on a heterogeneous complex network model," Applied Energy, vol. 194, pp. 648-657, 2017.

[13] D. Zhou, H. Li, Z. Li, J. Zhou, and D. Lin, "Structure characteristics analysis of diesel sales in complex network method," Cluster Computing, vol. 22, no. 3, pp. 5635-5635, 2019.

[14] S. Robinson, Z. Wang, and W. Martin, "Capturing the implications of services trade liberalization," Economic Systems Research, vol. 14, no. 1, pp. 3-33, 2002.

[15] B. Hoekman and A. Mattoo, "Services trade and growth," International Journal of Services Technology and Management, vol. 17, p. 1, 2008.

[16] J. Markusen, T. F. Rutherford, and D. Tarr, "Trade and direct investment in producer services and the domestic market for expertise," Canadian Journal of Economics/Revue Canadienne D'conomique, vol. 38, no. 3, pp. 758-777, 2005.

[17] P. W. Daniels, "Producer services research in the United Kingdom," The Professional Geographer, vol. 47, no. 1, pp. 82-87, 1995.

[18] B. Balassa, "Trade liberalisation and "revealed" comparative advantage," The Manchester School, vol. 33, no. 2, pp. 99-123, 1965.

[19] X. Liu and J. Shi, "A new method for interindustry linkage analysis based on demand-driven and multisector inputoutput model and its application in China's manufacturing and producer services," Complexity, vol. 2020, pp. 1-16, 2020.

[20] H. An, W. Zhong, Y. Chen, H. Li, and X. Gao, "Features and evolution of international crude oil trade relationships: a trading-based network analysis," Energy, vol. 74, pp. 254-259, 2014.

[21] M. A. Serrano and M. Boguna, "Topology of the world trade web," Physical Review E, vol. 68, Article ID 015101, 2003.

[22] D. Garlaschelli and M. I. Loffredo, "Structure and evolution of the world trade network," Physica A: Statistical Mechanics and Its Applications, vol. 355, no. 1, pp. 138-144, 2005.

[23] M. C. Mahutga, "The persistence of structural inequality? A network analysis of international trade, 1965-2000," Social Forces, vol. 84, pp. 1863-1889, 2006.

[24] L. De Benedictis and L. Tajoli, "The world trade network," The World Economy, vol. 34, no. 8, pp. 1417-1454, 2011.

[25] G. Fagiolo, J. Reyes, and S. Schiavo, "On the topological properties of the world trade web: a weighted network analysis," Physica A: Statistical Mechanics and Its Applications, vol. 387, no. 15, pp. 3868-3873, 2008.

[26] L. W. Jin, L. W. Kyung, S. S. Young, and Z. K. Gao, "Patent network analysis and quadratic assignment procedures to identify the convergence of robot technologies," PLoS One, vol. 11, Article ID e0165091, 2016.

[27] J. Huang, W. Zhang, and W. Ruan, "Spatial spillover and impact factors of the internet finance development in China," Physica a Statistical Mechanics and Its Applications, p. 527, 2019.

[28] T. Long, H. Pan, C. Dong, T. Qin, and P. Ma, "Exploring the competitive evolution of global wood forest product trade based on complex network analysis," Physica A: Statistical Mechanics and Its Applications, vol. 525, pp. 1224-1232, 2019.

[29] T. Kitamura and S. Managi, "Driving force and resistance: network feature in oil trade," Applied Energy, vol. 208, pp. 361-375, 2017.

[30] G. Fagiolo, J. Reyes, and S. Schiavo, "The evolution of the world trade web: a weighted-network analysis," Journal of Evolutionary Economics, vol. 20, no. 4, pp. 479-514, 2010.

[31] H. Xu and L. Cheng, "The qap weighted network analysis method and its application in international services trade," Physica A: Statistical Mechanics and Its Applications, vol. 448, pp. 91-101, 2016.

[32] H. Xu and L. Cheng, "The study of the influence of common humanistic relations on international services trade-from the perspective of multi-networks," Physica A: Statistical Mechanics and Its Applications, vol. 523, pp. 642-651, 2019.

[33] C. Yang, H. Wang, and Q. Han, "Identification of the structural characteristics and influencing factors of the international service trade network based on the sna method: empirical evidence from the Asia-Pacific region," International Business, pp. 65-75, 2017, in Chinese.

[34] H. L. Browning, J. Singelmann, and A. P. R. C. Texas Univ, The Emergence of a Service Society: Demographic and Sociological 
Aspects of the Sectoral Transformation of the Labor Force in the U.S.A.ERIC Clearinghouse, Washington, DC, USA, 1975.

[35] F. Cerina, Z. Zhu, A. Chessa, and M. Riccaboni, "World inputoutput network," PLoS One, vol. 10, 2015.

[36] Y. Yokura, H. Matsubara, and R. Sternberg, "R\&d networks and regional innovation: a social network analysis of joint research projects in Japan," Area, vol. 45, 2013.

[37] Z. Chong, C. Qin, and S. Pan, "The evolution of the belt and road trade network and its determinant factors," Emerging Markets Finance and Trade, vol. 55, no. 14, pp. 3166-3177, 2019.

[38] Bedassa, Tadesse, Roger, and White, "Cultural distance as a determinant of bilateral trade flows: do immigrants counter the effect of cultural differences?" Applied Economics Letters, 2009.

[39] Marjan, "Southeastern european trade analysis: a role for endogenous cefta-2006?" Emerging Markets Finance and Trade, vol. 49, pp. 26-44, 2013.

[40] W. T. Selmier and C. H. Oh, The Power of Major Trade Languages in Trade and Foreign Direct Investment, Social Science Electronic Publishing, Rochester, NY, USA.

[41] F. Kimura and H. H. Lee, "The gravity equation in international trade in services," Review of World Economics (Weltwirtschaftliches Archiv), p. 142, 2006.

[42] B. Kogut and H. Singh, "The effect of national culture on the choice of entry mode," Journal of International Business Studies, vol. 19, no. 3, pp. 411-432, 1988.

[43] W. Wang and Z. Li, "The evolution of China's interregional coal trade network, 1997-2016," Physica A: Statistical Mechanics and Its Applications, vol. 536, p. 120974, 2019.

[44] D. J. Watts and S. H. Strogatz, "Collective dynamics of 'smallworld' networks," Nature, vol. 393, no. 6684, pp. 440-442, 1998.

[45] Q. Wang, D. Du, Y. Zhang, and Q. Gui, "Research on the evolutionary characteristics of global mobile trade network," World Regional Studies, vol. 28, pp. 170-178, 2019, in Chinese.

[46] Y. Chen, "Social network analysis of the world trade pattern from 2000 to 2009," International Trade Issues, pp. 31-42, 2011, in Chinese. 